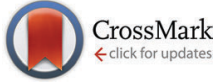

Cite this: Phys. Chem. Chem. Phys., 2016, 18, 7768

Received 7th December 2015 Accepted 10th February 2016

DOI: $10.1039 / c 5 c p 07523 h$

www.rsc.org/pccp

\title{
Synthesis of morphology-controlled bismutite for selective applications $\dagger$
}

\author{
Thangavel Selvamani, ${ }^{a}$ Balasubramaniam Gnana Sundara Raj, ${ }^{a}$ \\ Sambandam Anandan, ${ }^{* a}$ Jerry J. $\mathrm{Wu}^{\mathrm{b}}$ and Muthupandian Ashokkumar*c
}

Bismutite $\left(\mathrm{Bi}_{2} \mathrm{O}_{2} \mathrm{CO}_{3}\right)$ possessing diverse morphologies, namely nanosheets, nanodiscs and nanoplatelets, was synthesized by a simple controllable method using bismuth nitrate pentahydrate and urea as precursors in a water/ethylene glycol mixture. The as-synthesized samples showed unique physical and chemical properties, such as varying morphology, phase identification, chemical composition, surface area and surface potential. $\mathrm{Bi}_{2} \mathrm{O}_{2} \mathrm{CO}_{3}$ nanosheets exhibited excellent adsorption capabilities for anionic dyes (acid orange 7 and methyl orange) and high photocatalytic performance for the decolorization of cationic dyes (rhodamine $\mathrm{B}$ and methylene blue) under simulated solar illumination. Furthermore, the electrochemical performance of $\mathrm{Bi}_{2} \mathrm{O}_{2} \mathrm{CO}_{3}$ nanosheets showed good capacitance properties and hence could be a potential candidate for electrode materials in energy related applications.

\section{Introduction}

In general adsorption and photocatalysis are used in wastewater treatment (environmental remediation) for the removal/degradation of inorganic (heavy metals), organic (dyes, drugs and herbicides), and biological pollutants (virus and bacteria). ${ }^{1-5}$ Often, the selective adsorption of pollutants is a major issue and hence the development of better adsorbents is an active area of research. ${ }^{6}$ Zhu et al. successfully developed the selective adsorption of cationic dyes using anionic metal-organic frameworks through guest-guest exchange between mixtures of aqueous dye solutions. ${ }^{7}$ Ma et al. effectively prepared microporous anionic metal-organic frameworks for the selective adsorption of cationic dye from a mixture of organic dyes using the charge-selective separation ion exchange method. ${ }^{8}$ Both cases comprised topologically controlled structures. Over the past few years, innovative synthesis of various materials for dye adsorption and selective photocatalysis has been reported. ${ }^{5,9-22}$ The defects/oxygen vacancies play an important role in the

\footnotetext{
${ }^{a}$ Nanomaterials and Solar Energy Conversion Lab, Department of Chemistry, National Institute of Technology, Tiruchirappalli-620 015, India.

E-mail: sanand@nitt.edu; Fax: +91-431-2500133; Tel: +91-431-2503639

${ }^{b}$ Department of Environmental Engineering and Science, Feng Chia University, Taichung 407, Taiwan

${ }^{c}$ School of Chemistry, University of Melbourne, Vic 3010, Australia.

E-mail: masho@unimelb.edu.au; Fax: +61-3-93475180; Tel: +61-3-83447090

$\dagger$ Electronic supplementary information (ESI) available: (S1-S9) The FT-IR spectra of nanoplatelets and nanodiscs, the adsorption profile, XRD, FESEM and FT-IR spectra of $\mathrm{Bi}_{2} \mathrm{O}_{2} \mathrm{CO}_{3}$ nanosheets before and after adsorption/photocatalytic processes, photographic images showing adsorption/photocatalytic processes for dye solutions. Tables (ST1-ST5) show unit cell parameters, calculated $E_{\mathrm{VB}}$, $E_{\mathrm{CB}}$ from $E_{\mathrm{g}}$ values, $\mathrm{RR}(\%)$, adsorption capacities and comparison of adsorption profiles. See DOI: $10.1039 / \mathrm{c} 5 \mathrm{cp} 07523 \mathrm{~h}$
}

adsorption and photocatalytic behavior of these materials. ${ }^{10,12,16,17,22}$ Alternatively, oxygen-rich compounds showed better adsorption and photocatalytic properties due to their unique physicochemical properties. ${ }^{18,21}$ Nevertheless, the photocatalytic activity of a photocatalyst depends upon band gap, surface area, surface potential and morphologies exposed facets. ${ }^{23,24}$ Bismuth based oxides possess a narrow band gap, high charge carrier efficiency with good thermoelectric properties due to the overlap between $6 \mathrm{~s}(\mathrm{Bi})$ and $2 \mathrm{p}(\mathrm{O})$ of a valance band. ${ }^{25}$ Moreover, bismuth containing compounds have been used in many studies. ${ }^{6,17-22,24-27}$ Among these $\mathrm{Bi}_{2} \mathrm{O}_{2} \mathrm{CO}_{3}$ (bismutite) is an emerging material and used as an antibacterial, photocatalyst, sensor, supercapacitor, adsorbent and precursor for $\mathrm{Bi}_{2} \mathrm{O}_{3} \cdot{ }^{24,26,28-41}$ Bismutite belongs to Sillén phase compounds demonstrating inter-layer structures with alternative polymeric cationic $(\mathrm{BiO})_{n}{ }^{n+}$ and anionic $\left(\mathrm{CO}_{3}{ }^{2-}\right)$ layers and has been widely used as a photocatalyst for the degradation of toxic pollutants such as organic dyes and gaseous compounds such as nitric oxide (NO). ${ }^{26,29-34,40-48}$ Greaves et al. first reported the synthesis of $\mathrm{Bi}_{2} \mathrm{O}_{2} \mathrm{CO}_{3}$ through a simple chemical method and later, several methodologies have been reported for the synthesis of bismutite with various morphologies such as microflowers, microspheres (rose, plate, pinon-like, sponge-like, and hollow), persimmon-like, nanosheets, nanotubes, egg-tart and micro/nanostructures. ${ }^{28-37,42-55}$ Chen et al. reported the synthesis of bismuth micro/nanospheres by a simple chemical method using ethylene glycol as a non-toxic solvent. ${ }^{56}$ Numerous methods are available in the literature regarding the size and shape control of $\mathrm{Bi}_{2} \mathrm{O}_{2} \mathrm{CO}_{3}$ via solvothermal, surfactant-assisted hydrothermal and vacuum heat treatments. ${ }^{57-59}$ The concentration of precursors (citrate ion, nitrate ion, etc.), additives or precipitants (urea, sodium carbonate and ammonium 
carbonate, etc.) also plays a major role in achieving diverse morphologies of $\mathrm{Bi}_{2} \mathrm{O}_{2} \mathrm{CO}_{3}{ }^{60-63}$ Likewise, the effect of co-solvent (water/ethanol or water/ethylene glycol) for various other materials has been extensively studied in order to attain excellent physicochemical characteristics. ${ }^{64-66}$ These interesting approaches have also been implemented to attain tunable properties like surface area, surface potentials, band alignment with functional morphologies. ${ }^{65-69}$ Hence, researchers are interested to achieve multifunctional behavior with highly efficient and excellent selective applications through composition-structural engineering aspects. Until now, to the best of our knowledge, the synthesis of $\mathrm{Bi}_{2} \mathrm{O}_{2} \mathrm{CO}_{3}$ with mixed solvent (water/ethylene glycol) has not been reported and also extensively studied for selective applications. Herein, we report on the synthesis and characterization of $\mathrm{Bi}_{2} \mathrm{O}_{2} \mathrm{CO}_{3}$ with various morphologies through a simple and controllable method to explore their applications in dye adsorption and photocatalytic activity. In addition, the electrochemical performance of as-synthesized samples was tested to evaluate its suitability as a supercapacitor.

\section{Experimental}

\section{Chemicals}

All chemicals were of analytical grade and used without further purification. Bismuth(III) nitrate pentahydrate (ACS reagent, 98\%), urea (AR grade, 99\%), acid orange 7 (AO7: 85\%), methyl orange (MO; 85\%), methyl red (MR), rhodamine B (Rh B; 95\%), methylene blue (MB) and sodium sulfate were purchased from Sigma-Aldrich. Vulcan XC-72 and polyvinylidenefluoride (PVDF) were purchased from Fluka. $N$-Methyl-2-pyrrolidene (NMP), ethylene glycol ( $\geq 99 \%)$ and nitric acid (ACS reagent) were purchased from Merck.

\section{Synthesis of diverse bismutite nanostructures}

About $6.29 \mathrm{~g}$ of bismuth(III) nitrate pentahydrate was dissolved in $43 \mathrm{~mL}$ of ethylene glycol which was then mixed with $33 \mathrm{~mL}$ of urea solution $\left(6.05 \mathrm{~mol} \mathrm{dm}^{-3}\right)$ in a $100 \mathrm{~mL}$ round bottom flask. The initial $\mathrm{pH}$ of the reaction mixture was 1.2 , which was then adjusted to 0.9 using concentrated nitric acid $(2.1 \mathrm{~mL})$. Then, the reaction mixture was refluxed at $110{ }^{\circ} \mathrm{C}$ for $9 \mathrm{~h}$ under atmospheric pressure with constant stirring. After completion of the reaction, white bismutite nanosheet powder was collected and washed with distilled water several times and then dried at $80{ }^{\circ} \mathrm{C}$ for $4 \mathrm{~h}$. The nanoplatelet morphology was obtained by following similar experimental conditions but without the addition of concentrated nitric acid, whereas the nanodisc morphology was obtained by refluxing at $80{ }^{\circ} \mathrm{C}$ for $9 \mathrm{~h}$ keeping other conditions similar.

\section{Characterization}

The surface morphology was observed using a field emission scanning electron microscope (FESEM model JEOL 7401F) and a transmission electron microscope (TEM model JEOL JEM 2010). Chemical composition and elemental analysis were carried out using energy dispersive X-ray spectroscopy (EDS, Oxford Inc.).
The phase identification and crystal structures of the samples were determined by powder X-ray diffraction (XRD) using a Rigaku D/max-2500 diffractometer with a Ni-filtered $\mathrm{Cu} \mathrm{K} \alpha$ radiation source $(40 \mathrm{kV}, 30 \mathrm{~mA}, \lambda=1.5406 \AA)$. Fourier transform infrared (FTIR) spectra were recorded on a Nicolet iS50 infrared spectrophotometer using the $\mathrm{KBr}$ pellet technique. MicroRaman spectra of the sample were recorded by backscattering configuration using an EnSpectr RS-532 Raman system. X-ray photoelectron spectroscopy (XPS) measurements were recorded on a Physical Electronics PHI 5600 spectrophotometer with monochromatic $\mathrm{Al} \mathrm{K} \alpha(1486.6 \mathrm{eV}) \mathrm{X}$-ray as the excitation source. The nitrogen gas adsorption-desorption measurements were performed using a Micromeritics ASAP2010 at liquid nitrogen temperature $(77 \mathrm{~K})$ and surface area was calculated using the Brunauer-Emmett-Teller (BET) equation. Surface charge ( $\zeta$-potential) of the samples was measured at different $\mathrm{pH}$ values using a zeta-check-zeta-potential analyzer (Microtrac) apparatus. UV-visible absorption spectra (diffuse reflectance mode; DRS) were recorded using an ultraviolet-visible (UV-vis) spectrophotometer (T90+, PG instruments, UK) with an integrating sphere using $\mathrm{BaSO}_{4}$ as a standard. The photoluminescence (PL) spectra of the samples were performed using a Shimadzu (RF5301PC) spectrofluorometer at an excitation wavelength $(370 \mathrm{~nm})$ under ambient conditions. The photocurrent measurement was performed using an AUTOLAB12/FRA2 in a three-electrode system; as-synthesized samples were coated on FTO as a working electrode and platinum (Pt) the counter as well as reference electrode with polymer ion gel being used as a solid electrolyte under a xenon illumination source $(150 \mathrm{~W}$ with standard $85 \mathrm{~mW} \mathrm{~cm}^{-2}$ ).

\section{Adsorption studies}

Adsorption studies were performed by magnetically stirring the mixture at room temperature (natural $\mathrm{pH}$ ). In a typical process, $25 \mathrm{mg}$ of the samples was taken in a $125 \mathrm{ml}$ borosilicate glass bottle which contained $100 \mathrm{~mL}$ of organic dye solution $\left(1 \times 10^{-4} \mathrm{~mol} \mathrm{~L}^{-1}: \mathrm{AO} 7\right.$ and MO; $5 \times 10^{-5} \mathrm{~mol} \mathrm{~L}^{-1}: \mathrm{MR}, \mathrm{Rh} \mathrm{B}$ and $\mathrm{MB}$ ). The suspension was constantly stirred and at regular time intervals about $4 \mathrm{~mL}$ aliquots of reaction mixtures were removed and filtered using a PVDF syringe filter $(0.45 \mu \mathrm{m})$ to estimate the amount adsorbed. The amount of adsorbed dyes was quantified using a UV-vis spectrophotometer (T90+, PG instruments, UK). The removal ratios (RR) of adsorption for dyes was calculated using the formula $\mathrm{RR}=\left(C_{0}-C\right) / C_{0} \times 100 \%$. Then, the adsorption capacity of each dyes on the samples was calculated using $Q_{\mathrm{m}}=\left(C_{0}-C\right) \times V / m$. Here, the $Q_{\mathrm{m}}$ is the adsorption capacity $\left(\mathrm{mg} \mathrm{g}^{-1}\right), C_{0}$ and $C$ are the concentrations of the dye $\left(\mathrm{mg} \mathrm{L}^{-1}\right)$ before and after adsorption, respectively, $V$ is the volume of solution (L) and $m$ the mass of the samples taken (g). Furthermore, the selective adsorption of anionic dye (AO7 and $\mathrm{MO}$ ) from a mixture (AO7 in $\mathrm{MB}$ and $\mathrm{MO}$ in $\mathrm{MB}$ ) was studied under similar concentrations with as-synthesized samples as adsorbents.

\section{Photocatalytic activity}

Photocatalytic experiments of the synthesized samples were carried out at natural $\mathrm{pH}$ under ambient atmospheric conditions 
using a $150 \mathrm{~W}$ tungsten halogen lamp $(\lambda \geq 400 \mathrm{~nm}$; the intensity of incident radiation was $80600 \pm 10$ Lux measured using Extec, USA). The samples (50 mg of catalyst) were dispersed in a $125 \mathrm{~mL}$ borosilicate glass bottle which contained $100 \mathrm{~mL}$ of organic dye solution $\left(5 \times 10^{-5} \mathrm{~mol} \mathrm{~L}^{-1}: \mathrm{Rh} \mathrm{B}\right.$ and $\left.\mathrm{MB}\right)$. Prior to illumination, the suspension was magnetically stirred in the dark for $30 \mathrm{~min}$ to attain adsorption/desorption equilibrium. During irradiation, $4 \mathrm{~mL}$ of solution was collected at regular time intervals from the suspension mixtures and the catalyst was filtered using a PVDF syringe filter $(0.45 \mu \mathrm{m})$. The photocatalytic activity of synthesized samples was calculated by measuring the remaining concentration of organic dye using a UV-vis spectrophotometer (T90+, PG instruments, UK).

\section{Electrochemical measurements}

The working electrode was fabricated as described below: about 75 wt $\%$ bismutite, 20 wt $\%$ Vulcan XC-72 carbon (conductive agent) and $5 \mathrm{wt} \%$ of PVDF (binder) were ground in a mortar, and then a few drops of NMP solution was added to form a slurry. The slurry was then coated onto a pretreated SS plate (active electrode area was $1.0 \mathrm{~cm}^{2}$ ) and dried at $100{ }^{\circ} \mathrm{C}$ under vacuum for $12 \mathrm{~h}$. Capacitance measurements were performed using a standard three-electrode system containing the above prepared SS plate as a working electrode, Pt foil as a counter electrode, and $\mathrm{Ag} / \mathrm{AgCl}$ as a reference electrode in $1 \mathrm{M} \mathrm{Na}_{2} \mathrm{SO}_{4}$ aqueous solution as an electrolyte. Cyclic voltammetry (CV), galvanostatic (GV) charge-discharge and electrochemical impedance spectroscopy (EIS) techniques were performed at room temperature by using a potentiostat/galvanostat (AUTOLAB 302N module) as a testing system. The supercapacitor performance of the as-synthesized sample was measured at different scan rates $\left(5,10,20,40,80\right.$ and $\left.160 \mathrm{mV} \mathrm{s}^{-1}\right)$ within the potential range of -0.1 to $+0.4 \mathrm{~V}$. Then, a long term galvanostatic charge-discharge performance was carried out up to 1000 cycles at a current density of $0.1 \mathrm{~mA} \mathrm{~cm} \mathrm{~cm}^{-2}$ in the potential range of -0.1 to $+0.4 \mathrm{~V}$. The specific capacitance (SC) for as-prepared working electrodes was calculated from galvanostatic discharge curves using eqn (1).

$$
\mathrm{SC}=\frac{I t}{m \Delta E}
$$

where, $I$ is the current applied (amperes), $t$ is the discharging time in seconds, $m$ is the mass of the sample present on the electrode in grams and $\Delta E$ is the operating potential window in volts of charge and discharge. Furthermore, the electrochemical impedance spectroscopic measurements were carried out in the alternating current frequency range of $0.1 \mathrm{~Hz}-100 \mathrm{kHz}$ at open circuit voltage with an excitation signal of $10 \mathrm{mV}$ for an impedance spectrum analysis.

\section{Results and discussion}

\section{Microscopic observations}

Morphological features of the as-synthesized sample (refluxed at $110{ }^{\circ} \mathrm{C}$ for $9 \mathrm{~h}$ in the presence of concentrated nitric acid) are shown in Fig. 1a and b. The low magnification FESEM image
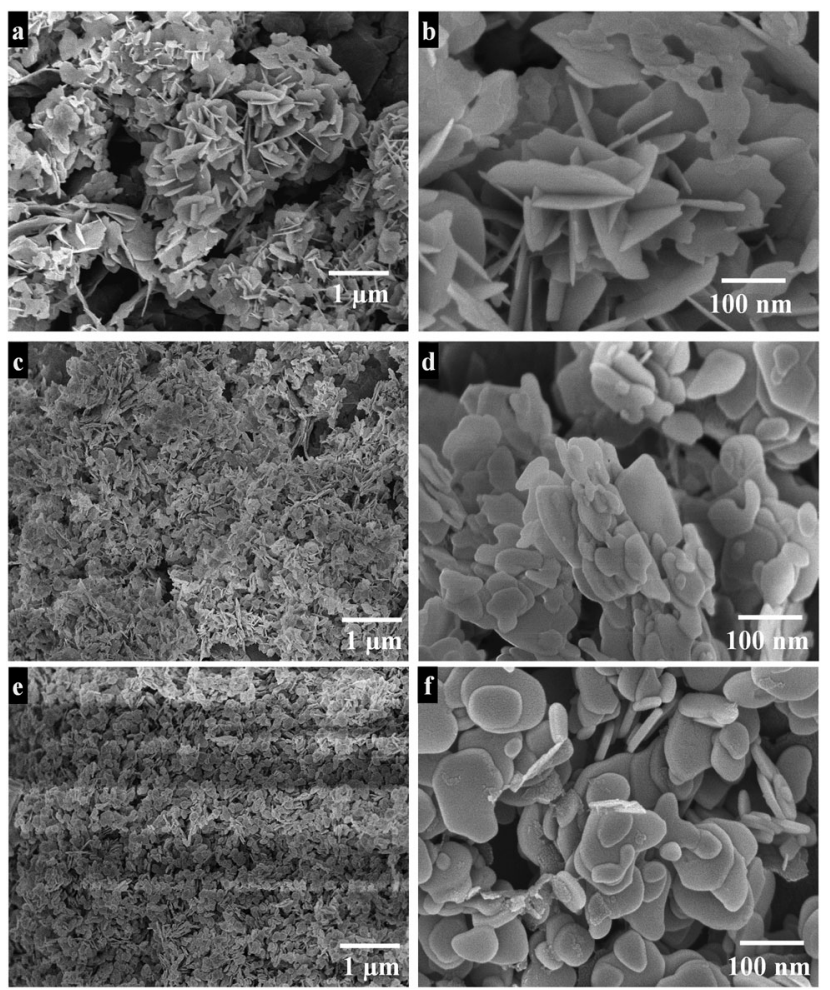

Fig. 1 Low and High magnification FESEM images of $\mathrm{Bi}_{2} \mathrm{O}_{2} \mathrm{CO}_{3}$ nanosheets ( $a$ and b), nanoplatelets ( $c$ and $d$ ) and nanodiscs ( $e$ and f).

(Fig. 1a) shows that the as-synthesized sample has a sheet-like morphology. A high magnification image (Fig. 1b) shows that each sheet is about $200-300 \mathrm{~nm}$ in length and 5-10 $\mathrm{nm}$ in thickness. Platelet-like morphology (Fig. 1c and d) is seen for the preparation procedure in the absence of concentrated nitric acid, while under similar reaction conditions, upon refluxing at $80{ }^{\circ} \mathrm{C}$ for $9 \mathrm{~h}$ disc-like morphology with 50-100 $\mathrm{nm}$ diameter and 10-15 $\mathrm{nm}$ thickness is produced (Fig. 1e and f). TEM results of the synthesized sample (refluxed at $110{ }^{\circ} \mathrm{C}$ for $9 \mathrm{~h}$ in the presence of concentrated nitric acid) reveal nanosheet morphology with immensely porous architecture and lateral dimensions of 200-300 $\mathrm{nm}$ in length and 300-500 $\mathrm{nm}$ in width (Fig. 2a and b). The observed lattice fringe $d$ space of $0.271 \mathrm{~nm}$ in HRTEM is in good agreement with the (110) plane of interplanar distance for nanosheets of bismutite (Fig. 2c). Furthermore, the selected area electron diffraction (SAED) patterns of nanosheets confirm that diffraction rings which are in good agreement with the polycrystalline nature of the tetragonal structure of bismutite (Fig. 2d). The EDS spectrum (Fig. 2e) of nanosheets shows the presence of $\mathrm{Bi}, \mathrm{C}$ and $\mathrm{O}$ elements confirming that synthesized material is pure $\mathrm{Bi}_{2} \mathrm{O}_{2} \mathrm{CO}_{3}$.

\section{Spectroscopic data}

Powder XRD patterns of as-synthesized samples are shown in Fig. 3. All diffraction lines can be indexed to the tetragonal phase of $\mathrm{Bi}_{2} \mathrm{O}_{2} \mathrm{CO}_{3}$ which are in good agreement with analogous JCPDS card no. 41-1488. Here, the distinct diffraction patterns at (20) 30.2, 32.6 and 46.8 lines correspond to (013), (110) and (020) 
a
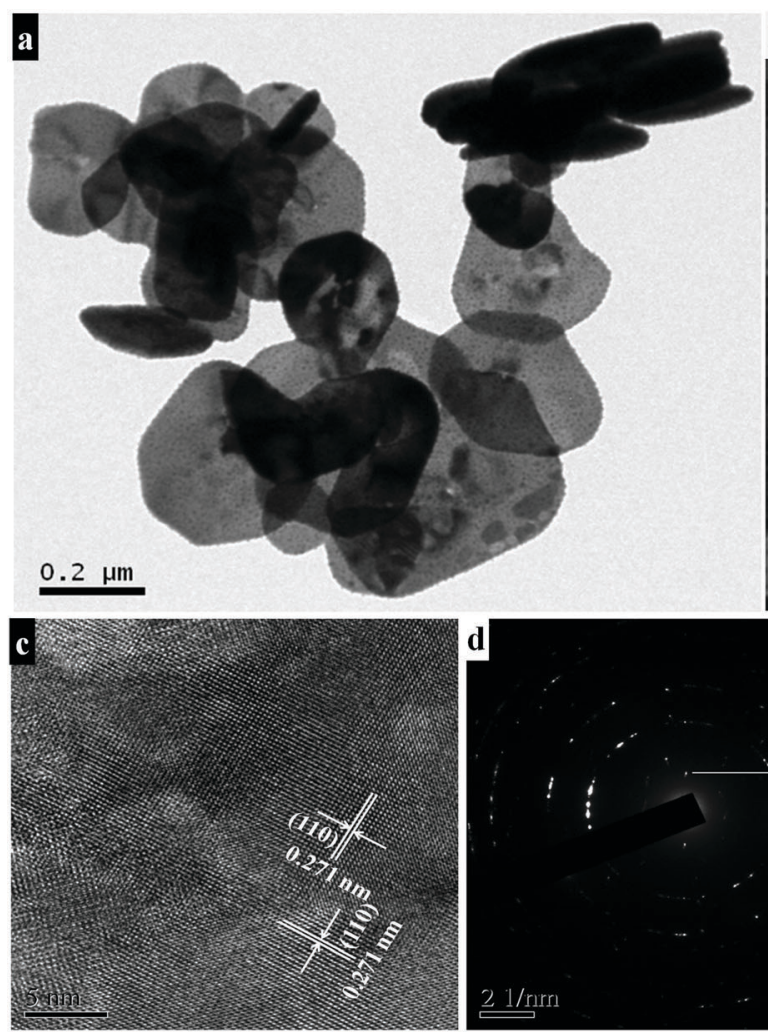
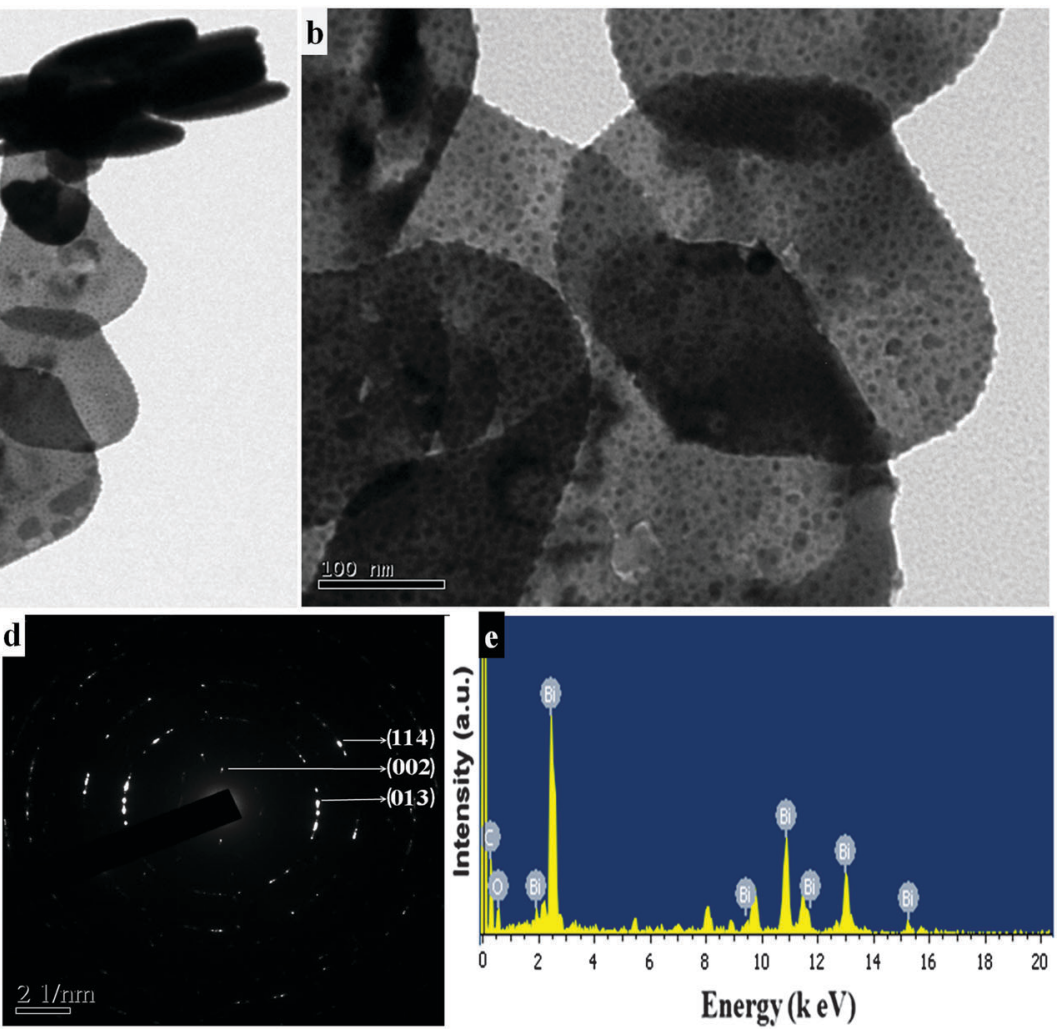

Fig. 2 TEM images ( $a$ and b), HRTEM image (c), SAED pattern (d) and EDS spectrum (e) of $\mathrm{Bi}_{2} \mathrm{O}_{2} \mathrm{CO}_{3}$ nanosheets.

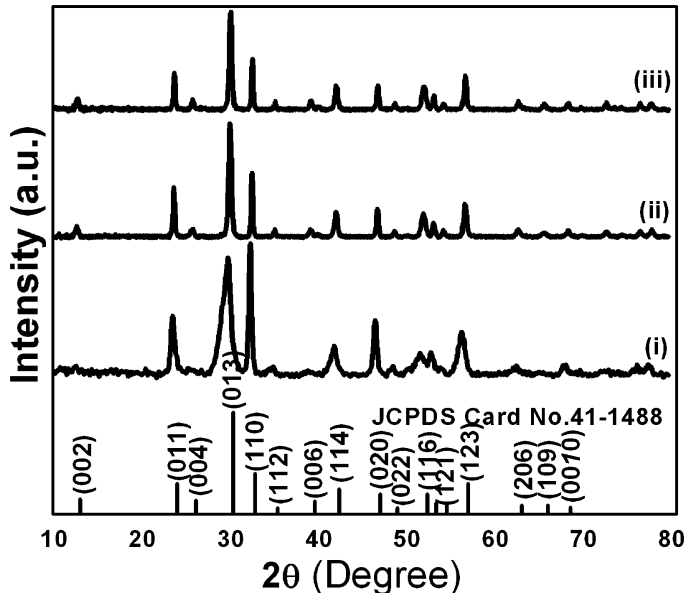

Fig. 3 Powder XRD patterns of $\mathrm{Bi}_{2} \mathrm{O}_{2} \mathrm{CO}_{3}$ nanosheets (i), nanoplatelets (ii) and nanodiscs (iii).

planes, respectively indicating the diverse nanostructures obtained during the reaction process. The intensity of diffraction lines attributes to the control over different growth orientations (crystallographic direction). ${ }^{17}$ In addition, the line broadening at 30.2 (013 plane) for nanosheets indicates smaller crystallites when compared with other morphologies. While all other morphologies show high crystallinity with the pure tetragonal phase of bismutite. The crystal sizes of as-synthesized samples are found to be 24, 28 and $29 \mathrm{~nm}$ for nanosheets, nanodiscs and nanoplatelets, respectively, calculated using Debye-Scherrer's formula for the most intense line at 30.2 (013 plane). The unit cell parameters of as-synthesized samples can be calculated using the least squares method and are given in Table ST1 (see ESI $\dagger$ ). The FTIR spectrum of nanosheets is shown in Fig. 4a. The spectrum confirms the presence of carbonate ion $\left(\mathrm{CO}_{3}{ }^{2-}\right)$ characteristic peaks which could be observed at $1036 \mathrm{~cm}^{-1}$ for symmetric vibration $\left(\nu_{1}\right), 1376 \mathrm{~cm}^{-1}$ and $1462 \mathrm{~cm}^{-1}$ (broad shoulder) for anti-symmetric vibration $\left(\nu_{3}\right), 838 \mathrm{~cm}^{-1}$ for outerplane bending $\left(\nu_{2}\right)$ and a shoulder at $690 \mathrm{~cm}^{-1}$ for inner-plane deformation $\left(\nu_{4}\right) .{ }^{30}$ Also, the additional vibration peak at $2424 \mathrm{~cm}^{-1}$ is attributed to the presence of carbonate ions. ${ }^{43}$ Other peaks at $3424 \mathrm{~cm}^{-1}$ and $1760 \mathrm{~cm}^{-1}$ could be assigned to the presence of surface $\mathrm{O}-\mathrm{H}$ stretching due to chemisorbed and/or physisorbed water molecules. No additional characteristic vibration peaks are observed under a typical synthetic process which confirms the purity of $\mathrm{Bi}_{2} \mathrm{O}_{2} \mathrm{CO}_{3}$. Similarly, the FT-IR spectra of nanodisc and nanoplatelet morphologies clearly indicate the formation of highly pure $\mathrm{Bi}_{2} \mathrm{O}_{2} \mathrm{CO}_{3}$ (Fig. S1, see ESI $\dagger$ ). Typical Raman spectra of $\mathrm{Bi}_{2} \mathrm{O}_{2} \mathrm{CO}_{3}$ nanosheets are shown in Fig. $4 \mathrm{~b}$ in which the characteristic peaks of $\mathrm{CO}_{3}{ }^{2-}$ ions are observed at 1360, 1070 and $670 \mathrm{~cm}^{-1}$, which could be attributed to $\nu_{3}, \nu_{1}$ and $\nu_{4}$ vibrations, respectively. The metal-oxygen $(\mathrm{Bi}=\mathrm{O})$ stretching vibration peak could be observed at $518 \mathrm{~cm}^{-1}$. Characteristic peaks at 161, 362 and $426 \mathrm{~cm}^{-1}$ are also obtained due to external vibration modes for Raman analysis. ${ }^{45,70}$ The crystal lattice of anions $\left(\mathrm{CO}_{3}{ }^{2-}\right)$ is hidden under the general positions $\left(C_{1}\right)$ for bismutite. Therefore, all vibrational modes become active for both FTIR and Raman analysis (degeneracies are removed). ${ }^{70}$ The chemical state of the elements 

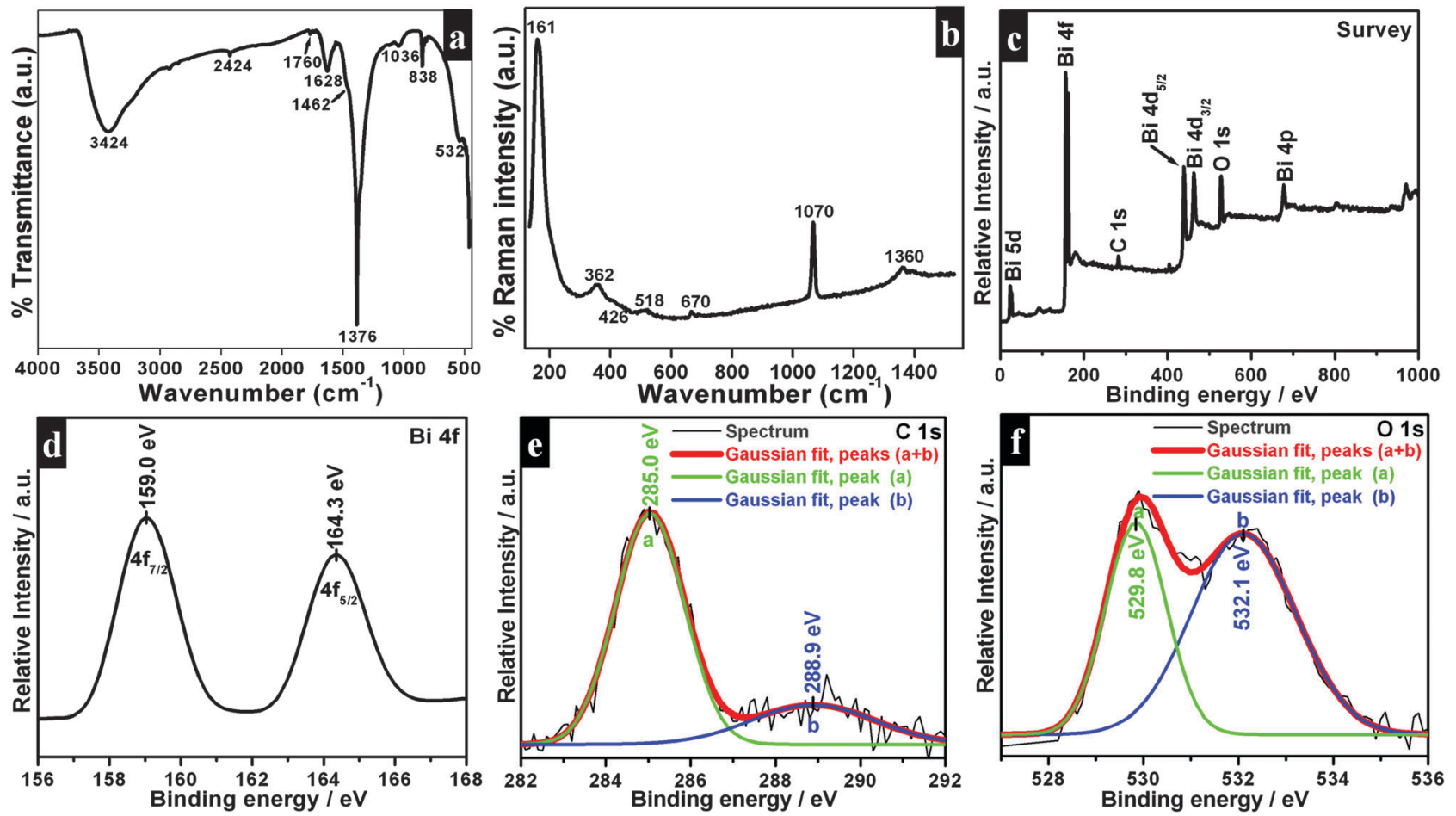

Fig. 4 FT-IR (a), Raman (b) and XPS spectrum (c-f) of $\mathrm{Bi}_{2} \mathrm{O}_{2} \mathrm{CO}_{3}$ nanosheets.

and surface compositions of as-synthesized $\mathrm{Bi}_{2} \mathrm{O}_{2} \mathrm{CO}_{3}$ nanosheets were confirmed by XPS (as shown in Fig. 4c-f). The survey spectrum (Fig. 4c) indicates the presence of $\mathrm{Bi}, \mathrm{C}$ and $\mathrm{O}$ elements, which are located at 160, 288 and $530 \mathrm{eV}$ for chemical binding energy states, respectively. Nevertheless, the core-level XPS signal of the Bi $4 \mathrm{f}$ element (Fig. 4d) displays two peaks at 159.0 and $164.3 \mathrm{eV}$ for $\mathrm{Bi} 4 \mathrm{f}_{7 / 2}$ and $\mathrm{Bi} 4 \mathrm{f}_{5 / 2}$ which could be assigned for spin-orbit splitting of $\mathrm{Bi}^{3+}$ in the $\mathrm{Bi}_{2} \mathrm{O}_{2} \mathrm{CO}_{3}$ sample. Although, $\mathrm{C}$ 1s spectra (Fig. 4e) obviously show two characteristic peaks at 285.0 and $288.9 \mathrm{eV}$ which are due to carbonate ions $\left(\mathrm{CO}_{3}{ }^{2-}\right)$ whereas the spectrum in
Fig. $4 \mathrm{f}$ demonstrates the $\mathrm{O} 1 \mathrm{~s}$ state, confirmed by two peaks at 529.8 and $532.1 \mathrm{eV}$ for Bi-O binding energy and carbonate ion species adsorbed with chemisorbed $\mathrm{OH}^{-}$in the water molecule on to the surface of the sample, respectively. ${ }^{31,45,46}$ Thus, the XPS spectrum also confirms that the as-synthesized sample is highly pure.

\section{Mechanism for the formation of diverse nanostructures}

A schematic illustration for the formation of bismutite with diverse morphologies is shown in Scheme 1. Reactions (2)-(5) show the formation of $\mathrm{Bi}_{2} \mathrm{O}_{2} \mathrm{CO}_{3} \cdot \mathrm{Bi}\left(\mathrm{NO}_{3}\right)_{3} \cdot 5 \mathrm{H}_{2} \mathrm{O}$ was dissolved

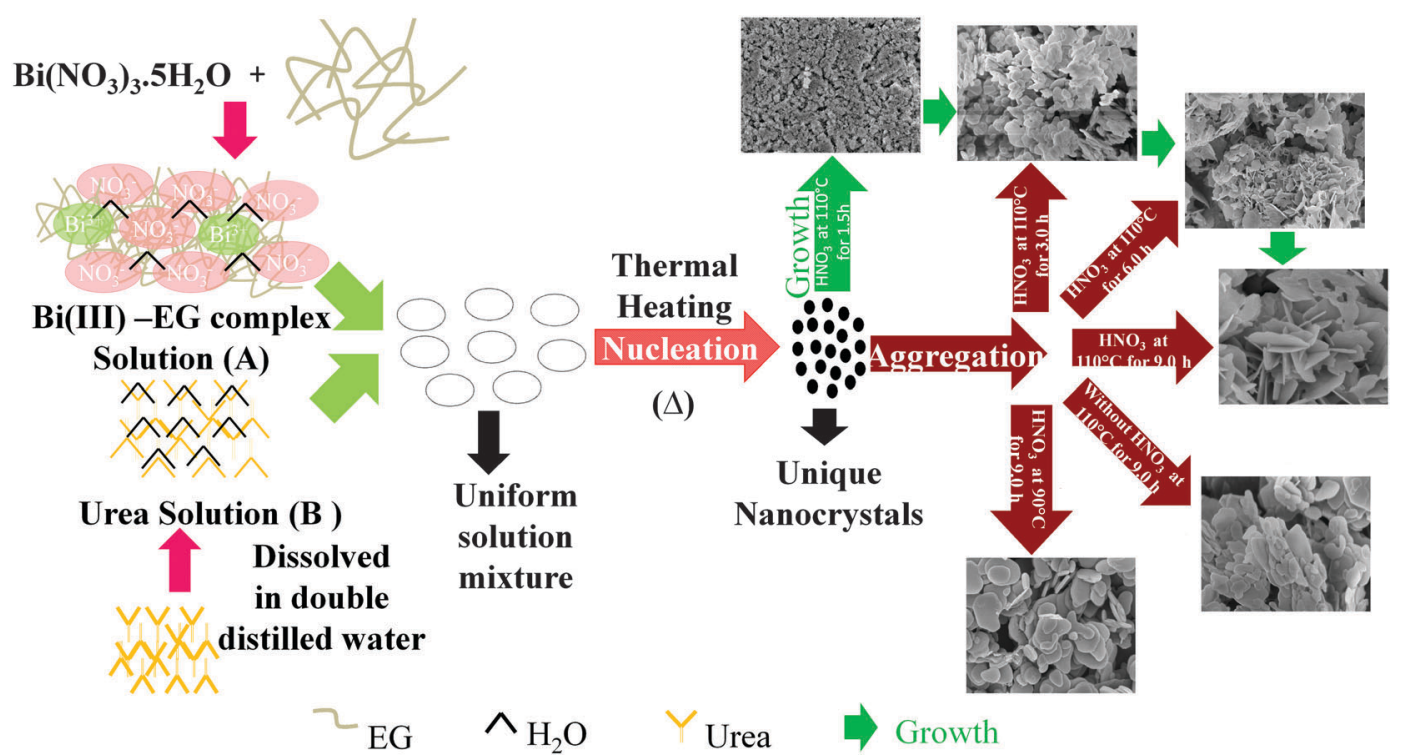

Scheme 1 Schematic illustration for the formation of diverse nanostructures of $\mathrm{Bi}_{2} \mathrm{O}_{2} \mathrm{CO}_{3}$. 
in ethylene glycol to produce glycolate complex solution (A) [reaction (2)]. ${ }^{71}$ Urea solution (B) was prepared by dissolving in double distilled water. When solutions (A) and (B) were mixed and heated to $110{ }^{\circ} \mathrm{C}$, urea underwent hydrolysis to produces $\mathrm{NH}_{4}{ }^{+}$and $\mathrm{OH}^{-}$ions [reactions (3) and (4)]. During the course of reaction, the glycolate complex reacted with the product to generate unique nanocrystals of $\mathrm{Bi}_{2} \mathrm{O}_{2} \mathrm{CO}_{3}$ [reaction (5)].

$$
\begin{gathered}
\mathrm{Bi}\left(\mathrm{NO}_{3}\right)_{3} \cdot 5 \mathrm{H}_{2} \mathrm{O}+3 \mathrm{HOCH}_{2} \mathrm{CH}_{2} \mathrm{OH} \\
\rightarrow \mathrm{Bi}\left(\mathrm{OCH}_{2} \mathrm{CH}_{2} \mathrm{OH}\right)_{3}+5 \mathrm{H}_{2} \mathrm{O}+3 \mathrm{HNO}_{3} \\
\mathrm{CO}\left(\mathrm{NH}_{2}\right)_{2}+\mathrm{H}_{2} \mathrm{O} \rightarrow 2 \mathrm{NH}_{3}+\mathrm{CO}_{2} \\
\mathrm{NH}_{3}+\mathrm{H}_{2} \mathrm{O} \rightarrow \mathrm{NH}_{4}^{+}+\mathrm{OH}^{-} \\
2 \mathrm{Bi}\left(\mathrm{OCH}_{2} \mathrm{CH}_{2} \mathrm{OH}\right)_{3}+\mathrm{CO}_{2}+12 \mathrm{OH}^{-} \\
\rightarrow \mathrm{Bi}_{2} \mathrm{O}_{2} \mathrm{CO}_{3}+6\left(\mathrm{HOCH}_{2} \mathrm{CH}_{2} \mathrm{OH}\right)+3 \mathrm{H}_{2} \mathrm{O}+3 \mathrm{O}_{2}
\end{gathered}
$$

Here, ethylene glycol acts as a complexing agent as well as a co-solvent. However, the addition of concentrated nitric acid to the reaction mixture leads to the controlled complex formation between $\mathrm{Bi}(\mathrm{III})$ and EG due to the common ion effect $\left(\mathrm{NO}_{3}{ }^{-}\right)$ which may affect the initial nucleation and growth to generate unique nanocrystals. ${ }^{9}$ As a result, thinner $\mathrm{Bi}_{2} \mathrm{O}_{2} \mathrm{CO}_{3}$ nanosheets are formed, whereas in the absence of concentrated nitric acid, intrinsic growth of nuclei leads to plate-like morphology. Experiments performed at lower temperature $\left(80{ }^{\circ} \mathrm{C}\right)$ leads to the formation of only disc-like morphology due to the much slower rate of production of $\mathrm{NH}_{4}{ }^{+}$and $\mathrm{OH}^{-}$ions from urea hydrolysis. In order to understand the nanosheet growth process, experiments were performed at different time periods $(1.5,3$ and $6 \mathrm{~h}$ ) under identical conditions. The obtained samples were analyzed by both SEM and powder XRD (Fig. 5). In the case of the $1.5 \mathrm{~h}$ experiment, the obtained product is only nanocrystals of $\mathrm{Bi}_{2} \mathrm{O}_{2} \mathrm{CO}_{3}$, whereas in the case of the $3 \mathrm{~h}$ experiment smaller nanocrystals aggregate into nanosheet-like morphology. In the case of the $6 \mathrm{~h}$ experiment nanosheet morphology is noticed due to Oswald ripping processes, whereas in the case of the $9 \mathrm{~h}$ experiment a well developed

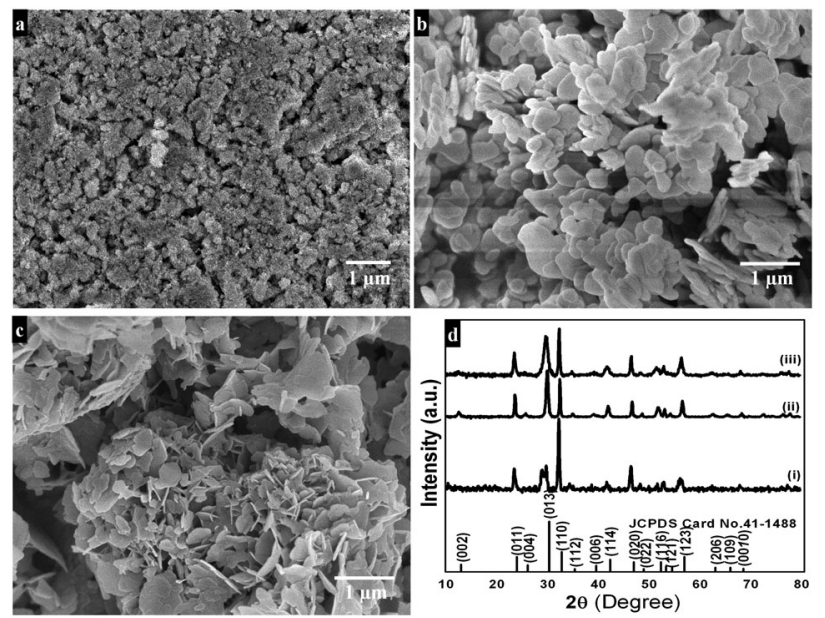

Fig. 5 FESEM images of $\mathrm{Bi}_{2} \mathrm{O}_{2} \mathrm{CO}_{3}$ nanosheets at $1.5 \mathrm{~h}(\mathrm{a}), 3.0 \mathrm{~h}$ (b) and $6.0 \mathrm{~h}$ (c). Powder XRD patterns of $\mathrm{Bi}_{2} \mathrm{O}_{2} \mathrm{CO}_{3}$ nanosheets (d) at $1.5 \mathrm{~h}$ (i), $3.0 \mathrm{~h}$ (ii) and $6.0 \mathrm{~h}$ (iii)
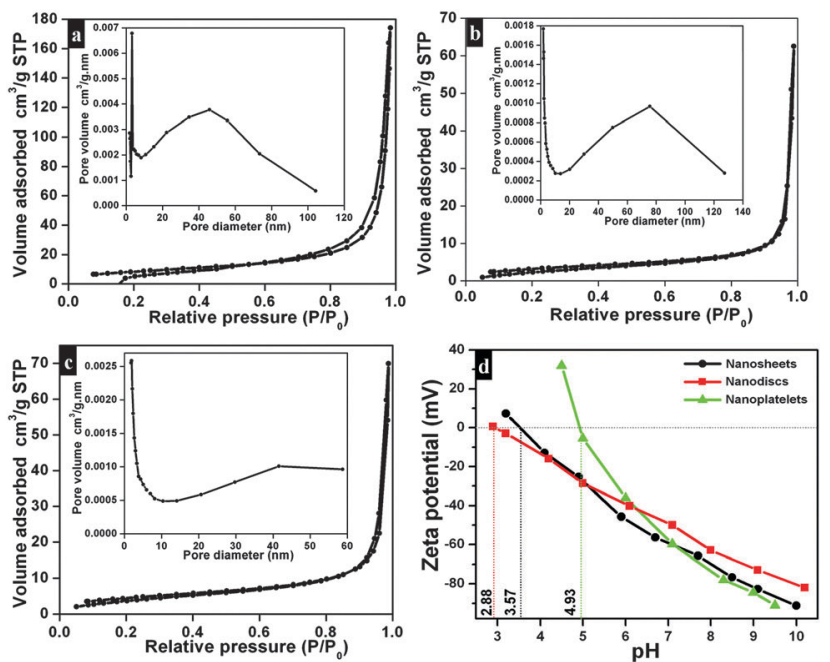

Fig. 6 Nitrogen gas adsorption/desorption isotherm of $\mathrm{Bi}_{2} \mathrm{O}_{2} \mathrm{CO}_{3}$ nanosheets (a), nanoplatelets (b) and nanodiscs (c) (inset shows $\mathrm{BHJ}$ pore size distribution curves for the appropriate samples). The $\zeta$-potential curve of $\mathrm{Bi}_{2} \mathrm{O}_{2} \mathrm{CO}_{3}$ nanosheets, nanoplatelets and nanodiscs (d)

product, i.e., $\mathrm{Bi}_{2} \mathrm{O}_{2} \mathrm{CO}_{3}$ nanosheets of $200-300 \mathrm{~nm}$ length and 5-10 $\mathrm{nm}$ thickness, is obtained. The powder XRD patterns also further support such nanosheet formation.

\section{Surface area, pore size distributions and $\zeta$-potential measurements}

The nitrogen $\left(\mathrm{N}_{2}\right)$ adsorption-desorption isotherms and BarrettJoyner-Halenda (BJH) pore size distribution of as-synthesized $\mathrm{Bi}_{2} \mathrm{O}_{2} \mathrm{CO}_{3}$ nanosheets are shown in Fig. 6a. The adsorption isotherms resemble type-III which possess a macroporous surface with monolayer-multilayer adsorption. Also the adsorption hysteresis loops clearly indicate $\mathrm{H} 3$ type without any limiting adsorption at high $P / P_{0}$ values which may be due to the existence of plate-like particles or slit-like pores. ${ }^{72,73}$ The calculated specific surface area of $\mathrm{Bi}_{2} \mathrm{O}_{2} \mathrm{CO}_{3}$ nanosheets is about $30 \mathrm{~m}^{2} \mathrm{~g}^{-1}$ calculated using the Brunauer-Emmett-Teller (BET) equation. The specific surface areas of $\mathrm{Bi}_{2} \mathrm{O}_{2} \mathrm{CO}_{3}$ nanoplatelet and nanodisc morphologies are about 11 and $16 \mathrm{~m}^{2} \mathrm{~g}^{-1}$, respectively (Fig. $6 \mathrm{~b}$ and c). The surface charges of as-synthesized $\mathrm{Bi}_{2} \mathrm{O}_{2} \mathrm{CO}_{3}$ samples were determined by $\zeta$-potential measurement: $\zeta$-potential $v$ s. $\mathrm{pH}$ is shown in Fig. 6d. It could be seen that it is positive at low $\mathrm{pH}$ and negative at high pH. The isoelectric point for all samples is below $\mathrm{pH} 7$.

\section{Adsorption of dyes}

The adsorption capacities of as-synthesized $\mathrm{Bi}_{2} \mathrm{O}_{2} \mathrm{CO}_{3}$ samples were evaluated by dispersing the samples in aqueous solutions containing dyes. $\mathrm{AO} 7, \mathrm{MO}, \mathrm{MR}, \mathrm{Rh} \mathrm{B}$ and $\mathrm{MB}$ were chosen as model dye pollutants. Fig. 7a-e show UV-vis absorption spectra of above mentioned dyes. The percentage of the adsorption profile (RR) reveals that about $96 \%$ of $\mathrm{AO} 7$ adsorbed on $\mathrm{Bi}_{2} \mathrm{O}_{2} \mathrm{CO}_{3}$ nanosheets in 60 min (Fig. 7a). The spectra shown in Fig. $7 \mathrm{~b}$ indicate that the rate of adsorption of $\mathrm{MO}$ on $\mathrm{Bi}_{2} \mathrm{O}_{2} \mathrm{CO}_{3}$ nanosheets is faster than that of $\mathrm{AO} 7$. However, only negligible amounts of neutral (MR) and cationic (Rh B and $\mathrm{MB}$ ) 

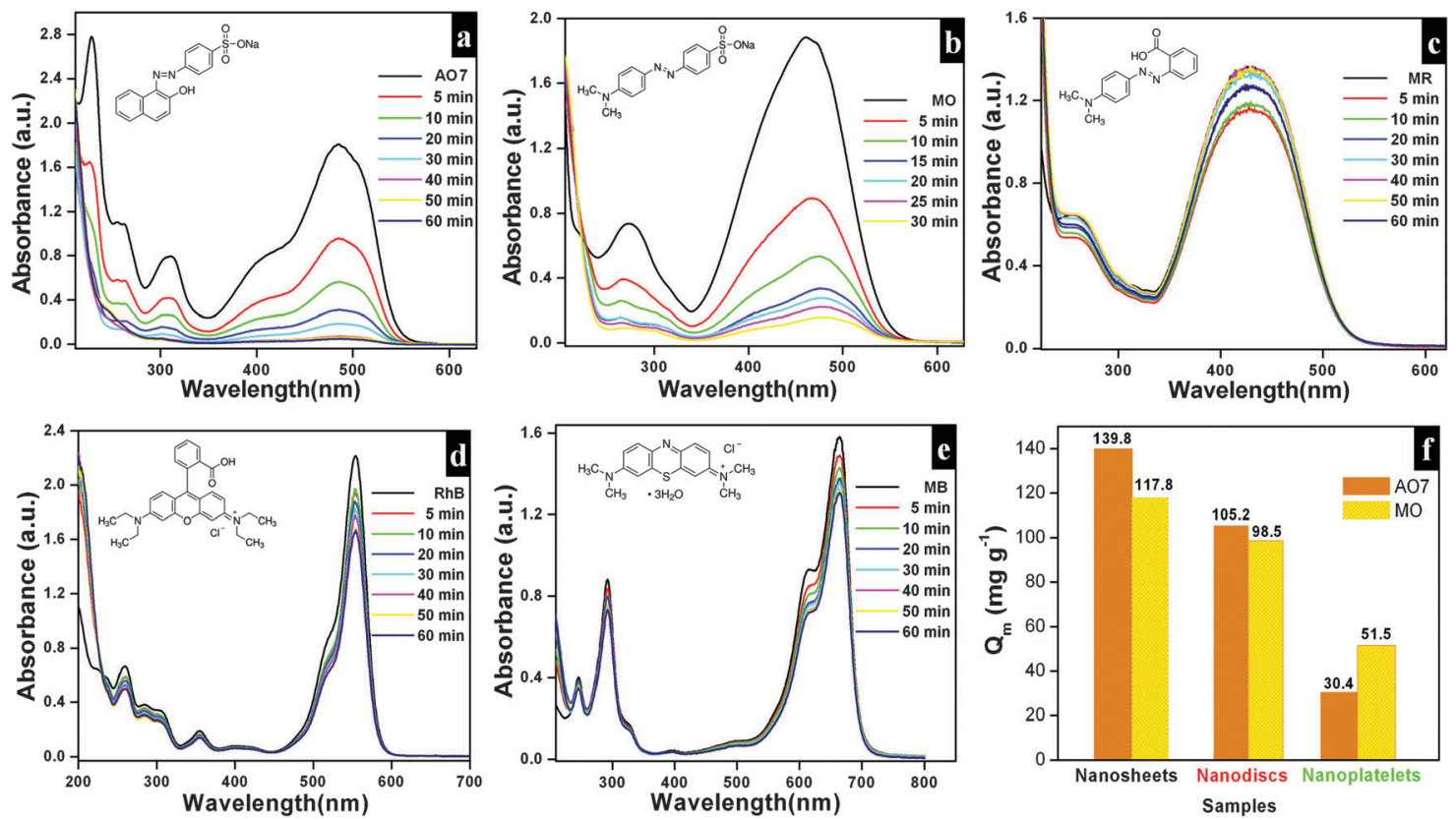

Fig. 7 Time dependence UV-vis absorption spectrum of $\mathrm{Bi}_{2} \mathrm{O}_{2} \mathrm{CO}_{3}$ nanosheets in the presence of $\mathrm{AO}$ (a), $\mathrm{MO}$ (b), $\mathrm{MR}(\mathrm{c}), \mathrm{Rh} \mathrm{B}(\mathrm{d})$ and $\mathrm{MB}$ (e) in the dark. The adsorption capacity profile for different morphologies of $\mathrm{Bi}_{2} \mathrm{O}_{2} \mathrm{CO}_{3}$ in the presence of $\mathrm{AO} 7$ and $\mathrm{MO}$ (f).

dyes were adsorbed on as-synthesized $\mathrm{Bi}_{2} \mathrm{O}_{2} \mathrm{CO}_{3}$ nanosheets (Fig. 7c-e). From the results, it could be suggested that $\mathrm{Bi}_{2} \mathrm{O}_{2} \mathrm{CO}_{3}$ nanosheets exhibit selective adsorption towards anionic dyes only. Likewise experiments performed with the other morphologies (nanodiscs and nanoplatelets) show a percentage of the adsorption profile (RR) of about 75 and $21 \%$ towards $\mathrm{AO} 7$ and $78 \%$ and $40 \%$ for MO under identical conditions (Fig. S2, see ESI $\dagger$ ). In addition, the adsorption capacities were calculated for as-synthesized samples and illustrated in Fig. 7f (statistical plot for $\mathrm{AO} 7$ and MO adsorption). Obviously, the nanosheets show enhanced adsorption capacity of $\mathrm{AO} 7$ about $139.8 \mathrm{mg} \mathrm{g}^{-1}$ which is significantly high compared with nanodiscs and nanoplatelets $\left(105.2 \mathrm{mg} \mathrm{g}^{-1}\right.$ and $30.4 \mathrm{mg} \mathrm{g}^{-1}$, respectively). Likewise, MO shows higher adsorption on nanosheets $\left(117.8 \mathrm{mg} \mathrm{g}^{-1}\right)$ compared to nanodiscs $\left(98.5 \mathrm{mg} \mathrm{g}^{-1}\right)$ and nanoplatelets $\left(51.5 \mathrm{mg} \mathrm{g}^{-1}\right)$. In order to explain the adsorption behavior of anionic, neutral and cationic dye molecules on as-synthesized $\mathrm{Bi}_{2} \mathrm{O}_{2} \mathrm{CO}_{3}$ a possible mechanism is proposed and illustrated in Scheme 2.

The observed negative $\zeta$-potential values $(-58,-49$ and $-59 \mathrm{mV}$ for nanosheets, nanodiscs and nanoplatelets) suggest that the prepared samples have $\mathrm{OH}$ groups adsorbed on the surface. ${ }^{74,75}$ In the case of anionic dye, adsorption is caused by electrostatic stabilization/interaction between the adsorbent (as-synthesized $\mathrm{Bi}_{2} \mathrm{O}_{2} \mathrm{CO}_{3}$ samples) and surface $\mathrm{OH}$ groups (negative $\zeta$-potential), whilst in the case of neutral and cationic dyes there are no such electrostatic stabilization/interactions. ${ }^{9,74}$ Molecular and microstructural level changes have taken place upon adsorption of anionic dye which could be confirmed by FESEM (undetermined morphology), FT-IR (characteristic band changes due to structural complexation) and powder XRD results (no changes in the tetragonal phase) (Fig. S3, see ESI $\dagger$ ). Also experiments were carried out under identical conditions to

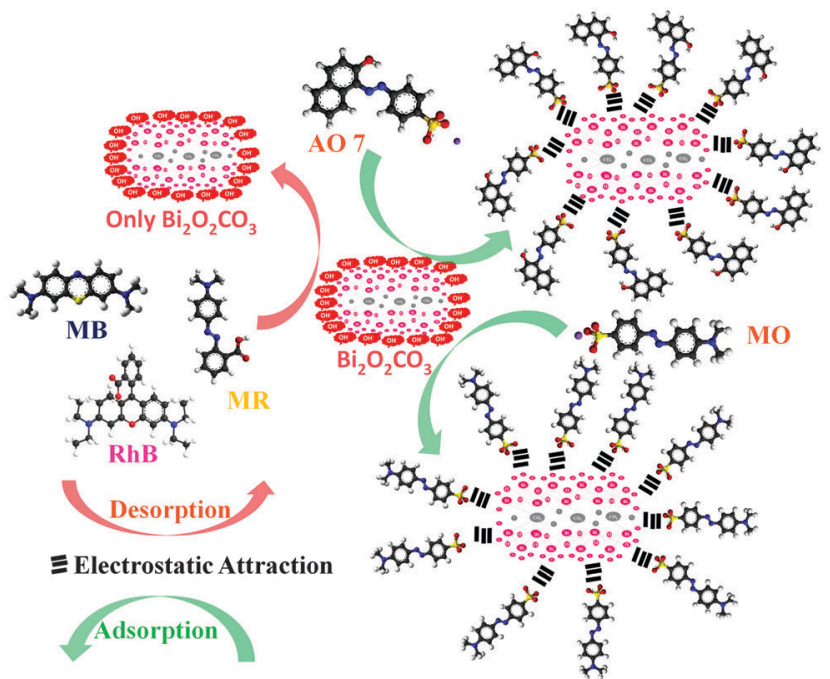

Scheme 2 Schematic representation of adsorption and desorption of dyes for as-synthesized $\mathrm{Bi}_{2} \mathrm{O}_{2} \mathrm{CO}_{3}$ samples.

understand the preferential adsorption of certain dye in a dye mixture. In the case of $\mathrm{AO} 7$ and $\mathrm{MB}$ dye mixtures $\mathrm{AO} 7$ is selectively adsorbed (Fig. 8a) whereas MO and MB dyes adsorb due to co-adsorption caused by the inductive effect of dye molecules (Fig. 8b). Nevertheless, for $\mathrm{AO} 7$ and $\mathrm{MB}$ dye mixtures such an inductive effect caused by the MB molecule is prevented due to the steric hindrance of the $\mathrm{AO} 7$ structure $(\mathrm{OH}$ functional group is in the cis position towards $-\mathrm{N}=\mathrm{N}$ - and the intra molecular hydrogen network) whereas in the MO molecular structure (the $-\mathrm{N}=\mathrm{N}$ - azo group is in the trans position between two aromatic rings) no such steric hindrance is observed. ${ }^{9}$ 

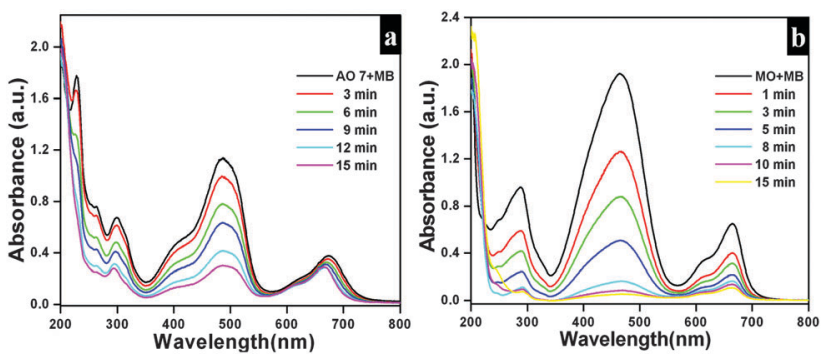

Fig. 8 (a) UV-vis absorption spectrum of $\mathrm{Bi}_{2} \mathrm{O}_{2} \mathrm{CO}_{3}$ nanosheets in the presence of $A O 7$ in $M B(a)$ and $M O$ in $M B(b)$.

\section{Photocatalytic activity and optical properties}

The photocatalytic efficiencies of as-synthesized samples were evaluated using Rh B and MB (cationic dyes) as model pollutants. Fig. 9a shows the absorption spectra observed for Rh B solution during photocatalytic degradation in the presence of $\mathrm{Bi}_{2} \mathrm{O}_{2} \mathrm{CO}_{3}$ nanosheets as a photocatalyst. Upon irradiation for $240 \mathrm{~min}$, the characteristic absorption peak at $553 \mathrm{~nm}$ for Rh B gradually decreased. The photocatalytic degradation efficiency $(D)$ for Rh B was calculated using eqn (6).

$$
D=\left(A / A_{0}\right) \times 100
$$

where $A$ and $A_{0}$ are $\mathrm{Rh} \mathrm{B}$ concentrations after and before degradation, respectively. For comparison, similar experiments were performed with $\mathrm{Bi}_{2} \mathrm{O}_{2} \mathrm{CO}_{3}$ nanodiscs and nanoplatelets and as well as without any catalyst (blank test) and the results are shown in Fig. $9 \mathrm{~b} . \mathrm{Bi}_{2} \mathrm{O}_{2} \mathrm{CO}_{3}$ nanosheets showed $98 \%$ decolorization of Rh B after 240 min under simulated solar illumination, while in the absence of a photocatalyst (blank test) only $3 \%$ decolorization was observed (Fig. 9b). For $\mathrm{Bi}_{2} \mathrm{O}_{2} \mathrm{CO}_{3}$ nanodisc and nanoplatelet morphologies about 80 and $70 \%$ decolorization of $\mathrm{Rh} \mathrm{B}$ were observed under identical conditions. The higher photocatalytic activity for $\mathrm{Rh} \mathrm{B}$ decolorization under $\mathrm{Bi}_{2} \mathrm{O}_{2} \mathrm{CO}_{3}$ nanosheets could be attributed to its high surface area $\left(30 \mathrm{~m}^{2} \mathrm{~g}^{-1}\right)$, morphology and distinct textural properties (negative $\zeta$-potential value). ${ }^{23,43}$ Similarly, the photocatalytic degradation of other cationic dye (MB) was performed under identical conditions using as-synthesized $\mathrm{Bi}_{2} \mathrm{O}_{2} \mathrm{CO}_{3}$ samples as the photocatalyst (Fig. S4, see ESI $\dagger$ ). $\mathrm{Bi}_{2} \mathrm{O}_{2} \mathrm{CO}_{3}$ nanosheets showed 95\% decolorization of MB after 600 min under illumination whereas 48 and $66 \%$ were observed in the case of nanoplatelets and nanodiscs, respectively (Fig. S4, see ESI $\dagger$ ). However, the photocatalysts do not show similar catalytic activity due to their molecular structure $(\mathrm{Rh} B$ has both partially positive and negative ions whereas MB has only positive ions). ${ }^{9,76}$ In addition, possible adsorption/desorption of the dye molecules with specific textural characteristics of $\mathrm{Bi}_{2} \mathrm{O}_{2} \mathrm{CO}_{3}$ samples influences the photocatalytic process. ${ }^{75}$ Furthermore, the effect of photocatalytic activity was explained by facilitated optical absorption/ emission characteristics (band gap/holes and electrons). The light absorption performance of $\mathrm{Bi}_{2} \mathrm{O}_{2} \mathrm{CO}_{3}$ samples is shown in Fig. 9c. In addition absorption coefficients of as-synthesized samples were examined by Tauc plots. The optical absorption band gap of the semiconductor was calculated using eqn (7). ${ }^{77}$

$$
\alpha=\frac{C\left(h \nu-E_{\mathrm{g}}^{\text {bulk }}\right)^{1 / 2}}{h \nu}
$$

where $\alpha$ is the absorption coefficient, $C$ is a constant, $h \nu$ is the photon energy and $E_{\mathrm{g}}^{\text {bulk }}$ is the band gap. The estimated band
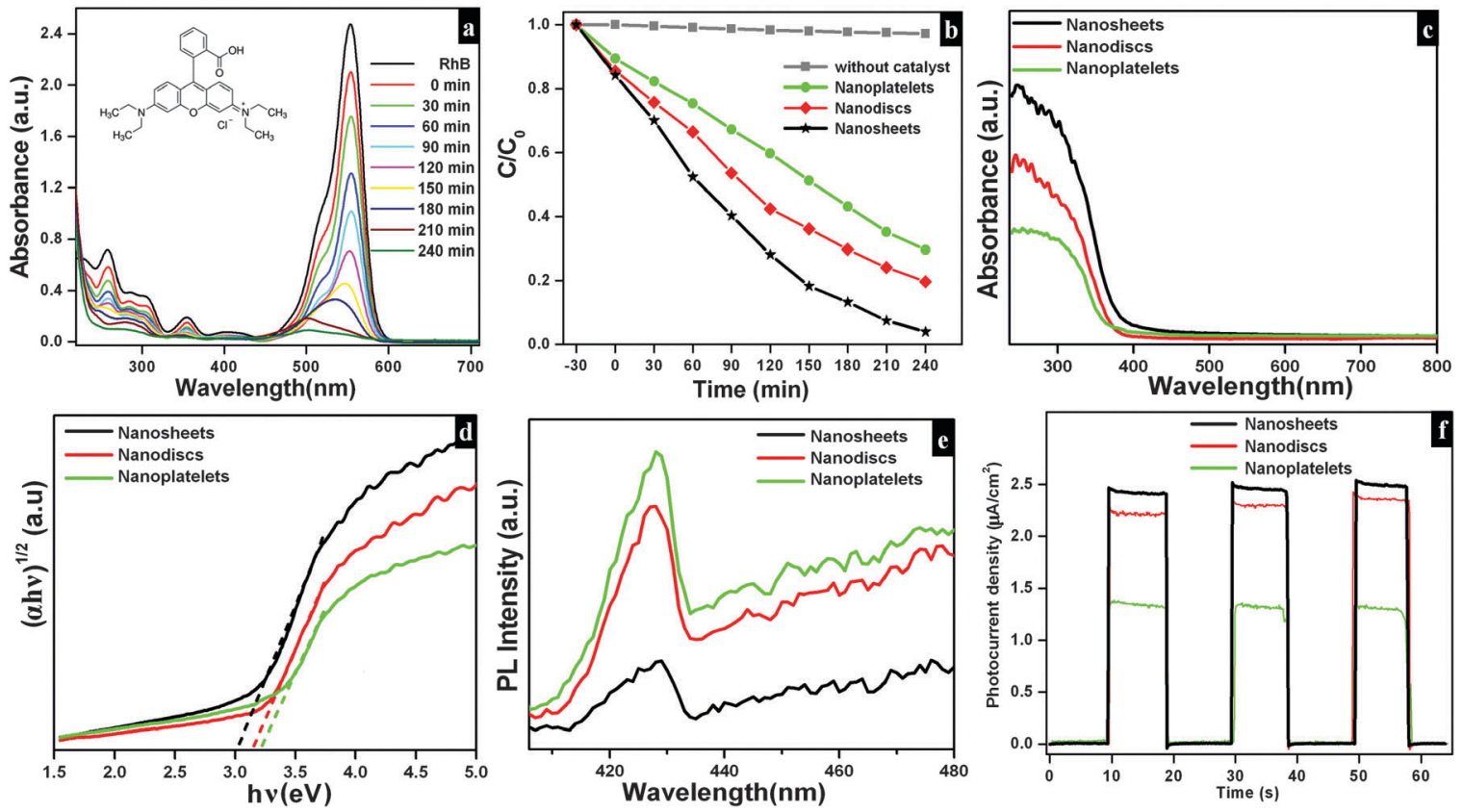

Fig. 9 Time dependence UV-vis absorption spectrum of $\mathrm{Bi}_{2} \mathrm{O}_{2} \mathrm{CO}_{3}$ nanosheets in the presence of $\mathrm{Rh} \mathrm{B}$ (a) under illumination. The photocatalytic degradation curve for different morphologies of $\mathrm{Bi}_{2} \mathrm{O}_{2} \mathrm{CO}_{3}$ in the presence of $\mathrm{Rh} \mathrm{B}$ (b). DRS absorption spectrum (c), corresponding Tauc plot (d), PL emission (e) and photocurrent responses ( $f$ ) of $\mathrm{Bi}_{2} \mathrm{O}_{2} \mathrm{CO}_{3}$ samples. 
gaps of as-synthesized $\mathrm{Bi}_{2} \mathrm{O}_{2} \mathrm{CO}_{3}$ samples are 3.02, 3.12 and $3.21 \mathrm{eV}$ for nanosheets, nanodiscs and nanoplatelets, respectively, by the extrapolation of the linear region of $(\alpha \mathrm{h} \nu)^{1 / 2}$ versus photon energy $h \nu$ plots (Fig. 9d). ${ }^{77}$ The emission spectra of as-synthesized $\mathrm{Bi}_{2} \mathrm{O}_{2} \mathrm{CO}_{3}$ show a strong emission peak at $428 \mathrm{~nm}\left(\lambda_{\mathrm{ex}}=370 \mathrm{~nm}\right)$, which could be attributed to photo-generated holes and electrons on the surface (Fig. 9e) ${ }^{78}$ The emission intensity of $\mathrm{Bi}_{2} \mathrm{O}_{2} \mathrm{CO}_{3}$ nanosheets is less intense due to the reduction in the recombination rate and separation of photogenerated carriers leading to a higher photocatalytic activity. ${ }^{22}$ To support this, photocurrent density measurements were performed for as-synthesized $\mathrm{Bi}_{2} \mathrm{O}_{2} \mathrm{CO}_{3}$ samples and are shown in Fig. 9f. $\mathrm{Bi}_{2} \mathrm{O}_{2} \mathrm{CO}_{3}$ nanosheets obviously showed a much higher photocurrent response, which implies superior photocatalytic activity than that of nanodiscs and nanoplatelets (Fig. 9f). Based on the results of these studies for photocatalytic activity, a mechanism is suggested in Scheme 3. Here, the valance band $(\mathrm{VB})$ and conduction band $(\mathrm{CB})$ potentials of as-synthesized $\mathrm{Bi}_{2} \mathrm{O}_{2} \mathrm{CO}_{3}$ samples can be calculated (Table ST2 (see $\mathrm{ESI} \dagger$ )) using the following eqn (8)-(9)

$$
\begin{gathered}
E_{\mathrm{VB}}=X-E_{\mathrm{e}}+0.5 E_{\mathrm{g}} \\
E_{\mathrm{CB}}=E_{\mathrm{VB}}-E_{\mathrm{g}}
\end{gathered}
$$

where $X$ is the absolute electronegativity of $\mathrm{Bi}_{2} \mathrm{O}_{2} \mathrm{CO}_{3}$, which is defined as the geometric average of the absolute electronegativities of the constituent atoms. $E_{\mathrm{e}}$ is the energy of free electrons on the hydrogen scale $\left(E_{\mathrm{e}}=4.5 \mathrm{eV}\right) . X$ was found to be $6.543 \mathrm{eV}$ for $\mathrm{Bi}_{2} \mathrm{O}_{2} \mathrm{CO}_{3}$. However, the positioned CB value at 0.438 to $0.533 \mathrm{eV}$ of as-synthesized $\mathrm{Bi}_{2} \mathrm{O}_{2} \mathrm{CO}_{3}$ samples given in Table ST2 ( $\mathrm{ESI} \dagger$ ) is more positive than that of $\mathrm{O}_{2} / \mathrm{O}_{2}{ }^{\bullet-}(-0.28 \mathrm{eV} v s$. NHE $)$ which implies that photoreduction through the electron and the position of ${ }^{\bullet} \mathrm{OH} / \mathrm{H}_{2} \mathrm{O}$ $(+2.27 \mathrm{eV}$ vs. NHE) displays more positive than that of the VB suggesting photooxidation through holes, respectively. Meanwhile, the dye molecules are stable under simulated solar illumination (without a catalyst) and in the presence of a photocatalyst (dark condition). Under illumination, the dye is excited and leading to electron injection from the excited state of the dye into the $\mathrm{CB}$ of the photocatalyst (self-sensitization degradation). ${ }^{79}$ In general, such photosensitization of photocatalysts is limited and follows the reactions proposed for photocatalytic degradation (reactions (10)-(14)). ${ }^{80}$

$$
\begin{gathered}
\text { Dye }+h \nu \rightarrow \text { Dye }^{*} \\
\mathrm{Bi}_{2} \mathrm{O}_{2} \mathrm{CO}_{3}+h \nu \rightarrow \mathrm{Bi}_{2} \mathrm{O}_{2} \mathrm{CO}_{3}\left(\mathrm{e}_{\mathrm{CB}}{ }^{-}\right)+\mathrm{Bi}_{2} \mathrm{O}_{2} \mathrm{CO}_{3}\left(\mathrm{~h}_{\mathrm{VB}}{ }^{+}\right) \\
\mathrm{H}_{2} \mathrm{O}+\mathrm{Bi}_{2} \mathrm{O}_{2} \mathrm{CO}_{3}\left(\mathrm{~h}_{\mathrm{VB}}{ }^{+}\right) \rightarrow \mathrm{Bi}_{2} \mathrm{O}_{2} \mathrm{CO}_{3}+\left({ }^{\bullet} \mathrm{OH}+\mathrm{H}^{+}\right) \\
\mathrm{O}_{2}+\mathrm{Bi}_{2} \mathrm{O}_{2} \mathrm{CO}_{3}\left(\mathrm{e}_{\mathrm{CB}}{ }^{-}\right) \rightarrow \mathrm{Bi}_{2} \mathrm{O}_{2} \mathrm{CO}_{3}+\left(\mathrm{O}_{2}{ }^{-}-\right) \\
\left({ }^{\bullet} \mathrm{OH}+\mathrm{H}^{+}\right)+\left(\mathrm{O}_{2}{ }^{-}-\right)+\text {Dye }^{*} \rightarrow \text { degradation products }
\end{gathered}
$$

The results of as-synthesized $\mathrm{Bi}_{2} \mathrm{O}_{2} \mathrm{CO}_{3}$ samples indicated that $E_{\mathrm{CB}}$ has more positive potential than that of Rh B dye (CB: $-1.42 \mathrm{eV}$ ) and the highest light absorption wavelength at $553 \mathrm{~nm}$ in the visible region possesses photo-generated electrons from the excited $\mathrm{Rh} \mathrm{B}$ (dye*) which leads to higher photocatalytic activity. ${ }^{81}$ Although the favorable light absorption of $\mathrm{Rh} \mathrm{B}$ and the amount of carboxylic groups $(-\mathrm{COOH})$ leading to the interaction with the surface site of the photocatalyst are much more when compared with $\mathrm{MB}$ (unavailable functional group), whereas, in the case of MB with the $\mathrm{CB}(-3.60 \mathrm{eV}$ vs. vacuum) with light absorption

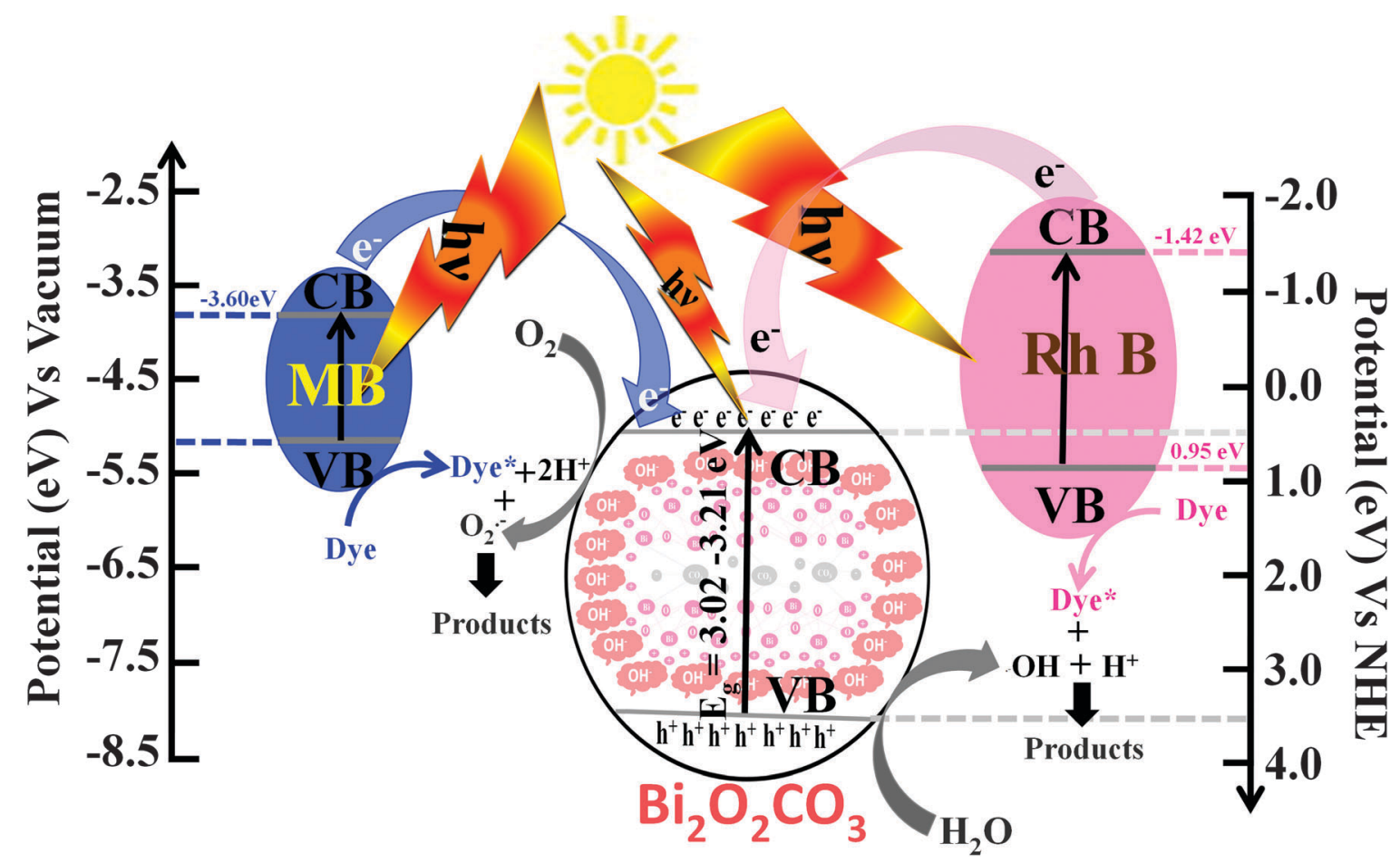

Scheme 3 Schematic demonstration showing the band structure and mechanism for the photocatalytic performances of dyes over as-synthesized $\mathrm{Bi}_{2} \mathrm{O}_{2} \mathrm{CO}_{3}$ samples under simulated solar illumination. 
at $664 \mathrm{~nm}$ apparently slower inclusion (week self-sensitization) for photo-generated electrons from the excited state and poor interaction with a photocatalyst surface site lead to lower photocatalytic activity. Therefore, as-synthesized $\mathrm{Bi}_{2} \mathrm{O}_{2} \mathrm{CO}_{3}$ samples might have higher photocatalytic activity for $\mathrm{Rh} B$ than MB caused by the self-sensitization degradation process upon simulated solar illumination. In addition, the photocatalytic effect for the dye degradation process indeed influenced their physical parameters such as band gap, surface area, surface potential and morphology of as-synthesized samples. ${ }^{23}$ Then, the materials' sustainability and reusability were studied after photodegradation by powder XRD, FESEM and FTIR analysis and the results are shown in Fig. S5 (see ESI $\dagger$ ).

\section{Electrochemical capacitance measurements}

Electrochemical performances of as-synthesized $\mathrm{Bi}_{2} \mathrm{O}_{2} \mathrm{CO}_{3}$ samples as electrode materials for a supercapacitor system were examined by cyclic voltammetry. Typical cyclic voltammogramms (Fig. 10a) are measured at a scan rate of $40 \mathrm{mV} \mathrm{s}^{-1}$ with potential ranging from -0.1 to $0.4 \mathrm{~V} v$ s. $\mathrm{Ag} / \mathrm{AgCl}$ in a $1 \mathrm{M} \mathrm{Na}_{2} \mathrm{SO}_{4}$ aqueous electrolyte exhibiting ideal capacitive characteristics (without any redox peak currents in curves). Here, $\mathrm{Bi}_{2} \mathrm{O}_{2} \mathrm{CO}_{3}$ nanosheet electrodes show greater integrated area and very high capacitance compared to nanodiscs and nanoplatelets. At different scan rates $(5,10,20,40$, 80 and $160 \mathrm{mV} \mathrm{s}^{-1}$ ) (Fig. 10b), the current response of electrode materials looks rectangular in shape with respect to the zerocurrent line and in addition peak current gets increased with increasing scan rates which illustrates the high capacitance (at low scan rate) and fast diffusion of ions (at a high scan rate). ${ }^{82-84}$
Hence, the specific capacitance of $\mathrm{Bi}_{2} \mathrm{O}_{2} \mathrm{CO}_{3}$ nanosheet electrodes decreases much low when scan rates increased as shown in Fig. 10c. Furthermore, the GV charge-discharge behaviour of $\mathrm{Bi}_{2} \mathrm{O}_{2} \mathrm{CO}_{3}$ nanosheet electrodes was examined using chronopotentiometry (CP) (potential ranges between -0.1 and $0.4 \mathrm{~V} v$ s. $\mathrm{Ag} / \mathrm{AgCl}$ in a $1 \mathrm{M} \mathrm{Na}_{2} \mathrm{SO}_{4}$ aqueous electrolyte and current density $0.1 \mathrm{~mA} \mathrm{~cm}{ }^{-2}$ ). The charging and discharging profiles of $\mathrm{Bi}_{2} \mathrm{O}_{2} \mathrm{CO}_{3}$ nanosheet electrodes are shown in linear variation (potential vs. time plot) which indicates that such material has high capacitance (Fig. 10d). The calculated specific capacitance value $\left(83.5 \mathrm{~F} \mathrm{~g}^{-1}\right.$ ) for $\mathrm{Bi}_{2} \mathrm{O}_{2} \mathrm{CO}_{3}$ nanosheet electrodes increases at higher cycles with the electrode surface being activated during the charging/discharging process. ${ }^{85}$ Furthermore, the mechanistic characteristics of EIS for as-synthesized $\mathrm{Bi}_{2} \mathrm{O}_{2} \mathrm{CO}_{3}$ samples were monitored. Fig. $10 \mathrm{f}$ shows the Nyquist impedance plots of as-synthesized samples exhibiting a semicircle over the high frequencies and a vertical line in the low frequencies. The semicircle at a high frequency range corresponds to the Faradaic charge transfer resistance $\left(R_{\mathrm{ct}}\right)$, which is mainly influenced by ionic resistances of the electrolyte and electrode active material interface. The vertical line at the low frequency range corresponds to ion diffusion of active electrode materials with respect to diffusive resistance at the electrolyte. ${ }^{85,86}$ Herein, $\mathrm{Bi}_{2} \mathrm{O}_{2} \mathrm{CO}_{3}$ nanosheet electrodes exhibiting a smaller semicircle at the high frequency region indicate that charge transfer resistance decreased extremely when compared with other electrodes such as nanodiscs and nanoplatelets. Hence, as-synthesized $\mathrm{Bi}_{2} \mathrm{O}_{2} \mathrm{CO}_{3}$ nanosheet electrodes showing excellent specific capacitance and good cycling stability with highly
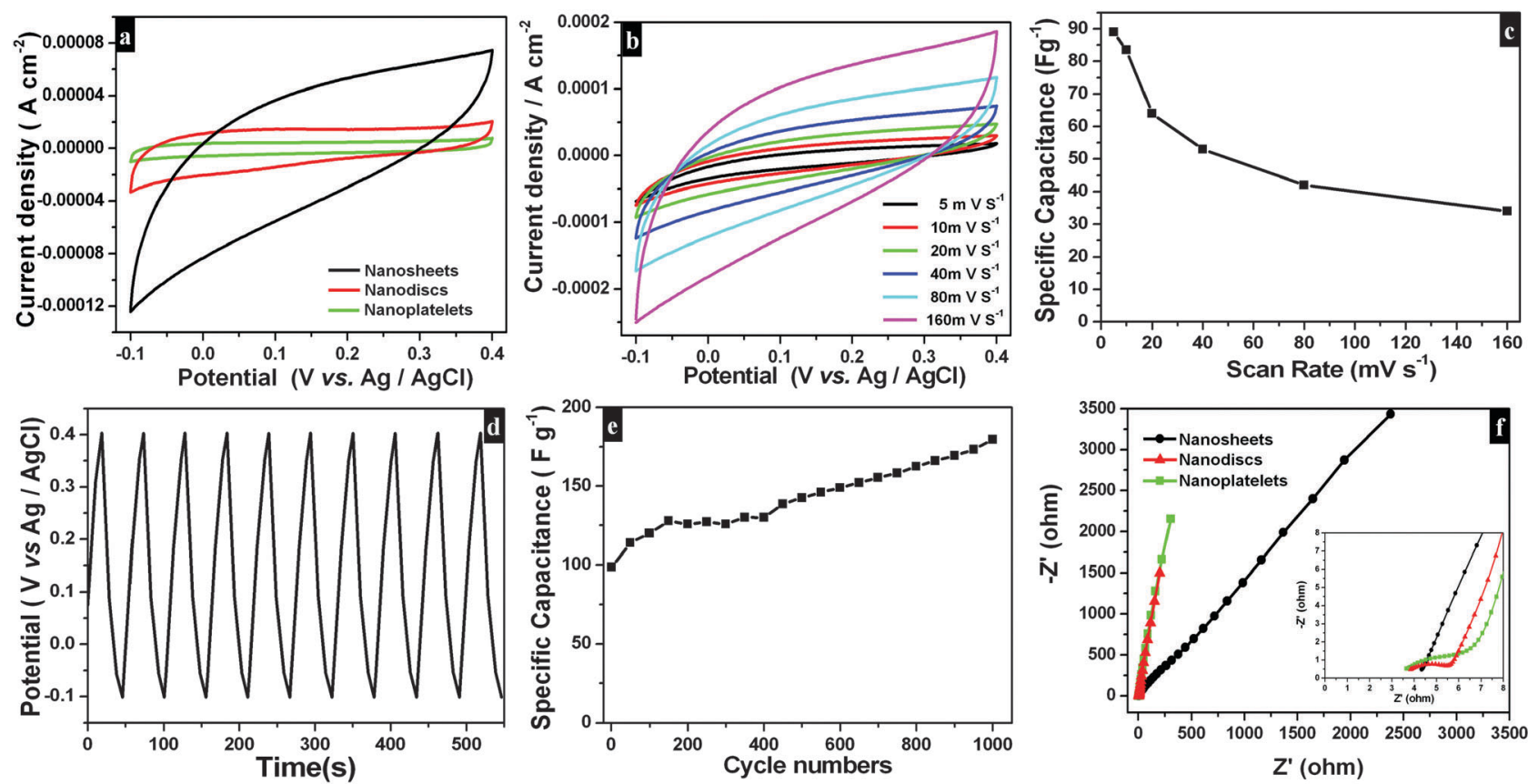

Fig. $10 \mathrm{CV}$ curves (a) for different morphologies of $\mathrm{Bi}_{2} \mathrm{O}_{2} \mathrm{CO}_{3}$ at $40 \mathrm{mV} \mathrm{s}^{-1}$ scan rate in $1 \mathrm{M} \mathrm{Na}_{2} \mathrm{SO}_{4}$ as an electrolyte. $\mathrm{CV}$ curves (b) and its corresponding specific capacitance plot (c) for $\mathrm{Bi}_{2} \mathrm{O}_{2} \mathrm{CO}_{3}$ nanosheets at different scan rates in the potential range of -0.1 to $0.4 \mathrm{~V} v \mathrm{vs}$. Ag/AgCl in an aqueous solution of $1 \mathrm{M} \mathrm{Na}_{2} \mathrm{SO}_{4}$ as an electrolyte. The galvanostatic charge-discharge cycling test (d) and specific capacitances for a number of cycles (e) of $\mathrm{Bi}_{2} \mathrm{O}_{2} \mathrm{CO}_{3}$ nanosheets at the current density $0.1 \mathrm{~mA} \mathrm{~cm}{ }^{-2}$. EIS plot (f) for different morphologies of $\mathrm{Bi}_{2} \mathrm{O}_{2} \mathrm{CO}_{3}$ at the high frequency region (inset shows the low frequency region). 
reversibility could be promising candidates as electrode materials in electrochemical supercapacitors as well as sensors and batteries.

\section{Conclusions}

In summary, $\mathrm{Bi}_{2} \mathrm{O}_{2} \mathrm{CO}_{3}$ with diverse morphologies was successfully synthesized using a simple controllable method. As-synthesized samples demonstrate a tetragonal structure with the well crystalline nature of $\mathrm{Bi}_{2} \mathrm{O}_{2} \mathrm{CO}_{3}$. It was observed that typical reaction parameters and reaction time provide a key factor for control over the morphologies of $\mathrm{Bi}_{2} \mathrm{O}_{2} \mathrm{CO}_{3}$ nanosheets, nanodiscs and nanoplatelets. The $\mathrm{N}_{2}$ adsorption and $\zeta$-potential measurements of the as-synthesized samples having surface areas 30, 16 and $11 \mathrm{mg} \mathrm{g}^{-1}$ (nanosheets, nanodiscs and nanoplatelets) with negative surface charge reveal the efficient adsorption of various dyes (selectively anionic dye) in aqueous solutions. Among them, $\mathrm{Bi}_{2} \mathrm{O}_{2} \mathrm{CO}_{3}$ nanosheets have excellent adsorption capacities of 139.8 and $117.8 \mathrm{mg} \mathrm{g}^{-1}$ for acid orange 7 and methyl orange dyes, respectively. Besides, these samples exhibit remarkable photocatalytic activity for the decolorization of cationic dyes (rhodamine $\mathrm{B}$ and methyleneblue) from the aqueous solution simulated solar illumination. Furthermore, the $\mathrm{Bi}_{2} \mathrm{O}_{2} \mathrm{CO}_{3}$ nanosheet sample shows a prominent specific electrochemical capacitance of $150 \mathrm{~F} \mathrm{~g}^{-1}$ after 400 cycles for supercapacitor applications. Thus, as-synthesized $\mathrm{Bi}_{2} \mathrm{O}_{2} \mathrm{CO}_{3}$ nanosheets can be excellent materials as adsorbents and photocatalysts for wastewater treatment with supercapacitor activities for energy applications.

\section{Acknowledgements}

The research described herein was financially supported by the Department of Science and Technology, India (GITA/DST/TWN/ P-50/2013) and National Science Council (NSC), Taiwan (NSC102-2923-035-001-MY3), under the India-Taiwan collaborative research grant.

\section{Notes and references}

1 I. Ali, Chem. Rev., 2012, 112, 5073-5091.

2 X. Chen, L. Liu, P. Y. Yu and S. S. Mao, Science, 2011, 331, 746-750.

3 H. Tong, S. Ouyang, Y. Bi, N. Umezawa, M. Oshikiri and J. Ye, Adv. Mater., 2012, 24, 229-251.

4 X. Qu, J. Brame, Q. Li and P. J. J. Alvarez, Acc. Chem. Res., 2013, 46, 834-843.

5 Q. Wu, X. Yang, J. Liu, X. Nie, Y. Huang, Y. Wen, J. Khan, W. U. Khan, M. Wu and T. An, ACS Appl. Mater. Interfaces, 2014, 6, 17730-17739.

6 F. Tian, J. Xiong, H. Zhao, Y. Liu, S. Xiao and R. Chen, CrystEngComm, 2014, 16, 4298-4305.

7 Z. Zhu, Y.-L. Bai, L. Zhang, D. Sun, J. Fang and S. Zhu, Chem. Commun., 2014, 50, 14674-14677.
8 Y.-C. He, J. Yang, W.-Q. Kan, H.-M. Zhang, Y.-Y. Liu and J.-F. Ma, J. Mater. Chem. A, 2015, 4, 1675-1681.

9 S. Wang, F. Teng and Y. Zhao, RSC Adv., 2015, 5, 76588-76598.

10 N. M. Tomić, Z. D. Dohčević-Mitrović, N. M. Paunivić, D. Ž. Mijin, N. D. Radić, B. V. Grbić, S. M. Aškrabic, B. M. Babić and D. V. Bajuk-Bogdanović, Langmuir, 2014, 30, 11582-11590.

11 A. Mills, M. Sheik, C. O'Rourke and M. McFarlane, Appl. Catal., B, 2009, 89, 189-195.

12 P. Ji, J. Zhang, F. Chen and M. Anpo, Appl. Catal., B, 2009, 85, 148-154.

13 S. Liang, R. Liang, L. Wen, R. Yuan, L. Wu and X. Fu, Appl. Catal., B, 2012, 125, 103-110.

14 M. Lazar and W. A. Daoud, RSC Adv., 2012, 2, 447-452.

15 C. Li, M. Wei, D. G. Evans and X. Duan, Small, 2014, 10, 4469-4486.

16 F. Liu, Y. H. Leung, A. B. Djurišić, A. M. C. Ng and W. K. Chan, J. Phys. Chem. C, 2013, 117, 12218-12228.

17 K. Ren, K. Zhang, J. Liu, H. Luo, Y. Huang and X. Yu, CrystEngComm, 2012, 14, 4384-4390.

18 X. Xiao, C. Liu, R. Hu, X. Zuo, J. Nan, L. Li and L. Wang, J. Mater. Chem., 2012, 22, 22840-22843.

19 F. Qin, G. Li, H. Xiao, Z. Lu, H. Sun and R. Chen, Dalton Trans., 2012, 41, 11263-11266.

20 C. F. Guo, J. Zhang and Q. Liu, ACS Nano, 2012, 6, 8746-8752.

21 Q.-C. Liu, D.-K. Ma, Y.-Y. Hu, Y.-W. Zeng and S.-M. Huang, ACS Appl. Mater. Interfaces, 2013, 5, 11927-11934.

22 Y. Huang, H. Li, M.-S. Balogun, W. Liu, Y. Tong, X. Lu and H. Ji, ACS Appl. Mater. Interfaces, 2014, 6, 22920-22927.

23 M. Roy, S. Ghosh and M. K. Naskar, Phys. Chem. Chem. Phys., 2015, 17, 10160-10169.

24 F. Wang, Z. Zhao, K. Zhang, F. Dong and Y. Zhou, CrystEngComm, 2015, 17, 6098-6102.

25 S. Sun and W. Wang, RSC Adv., 2014, 4, 47136-47512.

26 F. Qin, G. Li, R. Wang, J. Wu, H. Su and R. Chen, Chem. Eur. J., 2012, 18, 16491-16497.

$27 \mathrm{~J}$. Li, Y. Yu and L. Zhang, Nanoscale, 2014, 6, 8473-8488.

28 R. Chen, M. H. So, J. Yang, F. Deng, C.-M. Che and H. Sun, Chem. Commun., 2006, 2265-2267.

29 Y. Zheng, F. Duan, M. Chen and Y. Xie, J. Mol. Catal. A: Chem., 2010, 317, 34-40.

30 F. Dong, W.-K. Ho, S. C. Lee, Z. Wu, M. Fu, S. Zou and Y. Huang, J. Mater. Chem., 2011, 21, 12428-12436.

31 P. Madhusudan, J. Zhang, B. Cheng and G. Liu, CrystEngComm, 2013, 15, 231-240.

32 T. Selvamani, A. M. Asiri, A. O. Al-Youbi and S. Anandan, Mater. Sci. Forum, 2013, 764, 169-193.

33 T. Xiong, F. Dong and Z. Wu, RSC Adv., 2014, 4, 56307-56312.

34 Z. Zhao, Y. Zhou, F. Wang, K. Zhang, S. Yu and K. Cao, ACS Appl. Mater. Interfaces, 2015, 7, 730-737.

35 H. Huang, J. Wang, F. Dong, Y. Guo, N. Tian, Y. Zhang and T. Zhang, Cryst. Growth Des., 2015, 15, 534-537.

36 Y. Zhou, H. Wang, M. Sheng, Q. Zhang, Z. Zhao, Y. Lin, H. Liu and G. R. Patzke, Sens. Actuators, B, 2013, 188, 1312-1318. 
37 S. Peng, L. Li, H. Tan, Y. Wu, R. Cai, H. Yu, X. Huang, P. Zhu, S. Ramakrishna, M. Srinivasan and Q. Yan, J. Mater. Chem. A, 2013, 1, 7630-7638.

38 D. Barreca, F. Morazzoni, G. A. Rizzi, R. Scotti and E. Tondello, Phys. Chem. Chem. Phys., 2001, 3, 1743-1749.

39 X. Zhang, Y. Zheng, D. G. McCulloch, L. Y. Yeo, J. R. Friend and D. R. MacFarlane, J. Mater. Chem. A, 2014, 2, 2275-2282.

40 H.-Y. Jiang, P. Li, G. Liu, J. Ye and J. Lin, J. Mater. Chem. A, 2015, 3, 5119-5125.

41 J. Eberl and H. Kisch, Photochem. Photobiol. Sci., 2008, 7, 1400-1406.

42 P. Taylor, S. Sunder and V. J. Lopata, Can. J. Chem., 1984, 62, 2863-2873.

43 H. Cheng, B. Huang, K. Yang, Z. Wang, X. Qin, X. Zhang and Y. Dai, ChemPhysChem, 2010, 11, 2167-2173.

44 L. Chen, R. Huang, S.-F. Yin, S.-L. Luo and C.-T. Au, Chem. Eng. J., 2012, 193-194, 123-130.

45 F. Dong, S. C. Lee, Z. Wu, Y. Huang, M. Fu, W.-K. Ho, S. Zou and B. Wang, J. Hazard. Mater., 2011, 195, 346-354.

46 F. Dong, Y. Sun, M. Fu, W.-K. Ho, S. C. Lee and Z. Wu, Langmuir, 2012, 28, 766-773.

47 F. Dong, A. Zheng, Y. Sun, M. Fu, B. Jiang, W.-K. Ho, S. C. Lee and Z. Wu, CrystEngComm, 2012, 14, 3534-3544.

48 F. Dong, Y. Sun, W.-K. Ho and Z. Wu, Dalton Trans., 2012, 41, 8270-8284.

49 F. Dong, J. Bian, Y. Sun, T. Xiong and W. Zhang, CrystEngComm, 2014, 16, 3592-3604.

50 Y. Liu, Z. Wang, B. Huang, K. Yang, X. Zhang, X. Qin and Y. Dai, Appl. Surf. Sci., 2010, 257, 172-175.

51 R. Chen, G. Cheng, M. H. So, J. Wu, Z. Lu, C.-M. Che and H. Sun, Mater. Res. Bull., 2010, 45, 654-658.

52 X.-F. Cao, L. Zhang, X.-T. Chen and Z.-L. Xue, CrystEngComm, 2011, 13, 1939-1945.

53 T. Zhao, J. Zai, M. Xu, Q. Zou, Y. Su, K. Wang and X. Qian, CrystEngComm, 2011, 13, 4010-4017.

54 F. Dong, Q. Li, W. Zhang, M. Guan, W.-K. Ho and Z. Wu, Mater. Chem. Phys., 2013, 142, 381-386.

55 L. Yang, Q. Han, J. Zhu and X. Wang, Mater. Lett., 2015, 138, 235-237.

56 G. Cheng, J. Wu, F. Xiao, H. Yu, Z. Lu, X. Yu and R. Chen, Mater. Lett., 2009, 63, 2239-2242.

57 G. Cheng, H. Yang, K. Rong, Z. Lu, X. Yu and R. Chen, J. Solid State Chem., 2010, 183, 1878-1883.

58 H. Y. Liang, Y. X. Yang, J. C. Tang and M. Ge, Mater. Sci. Semicond. Process., 2013, 16, 1650-1654.

59 F. Dong, T. Xiong, Y. Sun, H. Huang and Z. Wu, J. Mater. Chem. A, 2015, 3, 18466-18474.

60 J. Tang, H. Zhao, G. Li, Z. Lu, S. Xiao and R. Chen, Ind. Eng. Chem. Res., 2013, 52, 12604-12612.

61 S. Liu, Y. Tu and G. Dai, Ceram. Int., 2014, 40, 2343-2348.
62 W. Cen, T. Xiong, C. Tang, S. Yuan and F. Dong, Ind. Eng. Chem. Res., 2014, 53, 15002-15011.

63 F. Dong, H. Liu, W.-K. Ho, M. Fu and Z. Wu, Chem. Eng. J., 2013, 214, 198-207.

64 C.-M. Lan, S.-E. Liu, J.-W. Shiu, J.-Y. Hu, M.-H. Lin and E. W.-G. Diau, RSC Adv., 2013, 3, 559-565.

65 T. Selvamani, T. Yagyu, S. Kawasaki and I. Mukhopadhyay, Catal. Commun., 2010, 11, 537-541.

66 T. Selvamani, C. A. Manjula, S. Anandan, A. M. Asiri and M. Ashokkumar, Cryst. Res. Technol., 2015, 50, 143-149.

67 H. Huang, K. Xiao, S. Yu, F. Dong, T. Zhang and Y. Zhang, Chem. Commun., 2016, 52, 354-357.

68 L. Shan, G. Wang, D. Li, X. San, L. Liu, L. Dong and Z. Wu, Dalton Trans., 2015, 44, 7835-7843.

69 H. Huang, X. Li, J. Wang, F. Dong, P. K. Chu, T. Zhang and Y. Zhang, ACS Catal., 2015, 5, 4094-4103.

70 G. E. Tobon-Zapata, S. B. Etcheverry and E. J. Baran, J. Mater. Sci. Lett., 1997, 16, 656-657.

71 X. Xiao, R. Hu, C. Liu, C. Xing, C. Qian, X. Zuo, J. Nan and L. Wang, Appl. Catal., B, 2013, 140-141, 433-443.

72 K. S. W. Sing, D. H. Everett, R. A. W. Haul, L. Moscou, R. A. Pierotti, J. Rouquérol and T. Siemieniewska, Pure Appl. Chem., 1985, 57, 603-619.

73 K. Kaneko, J. Membr. Sci., 1994, 96, 59-89.

74 C. Pan, J. Xu, Y. Chen and Y. Zhu, Appl. Catal., B, 2012, 115-116, 314-317.

75 S. Obregón and G. Colón, J. Mol. Catal. A: Chem., 2013, 376, 40-47.

76 Y. Lei, G. Wang, S. Song, W. Fan, M. Pang, J. Tang and H. Zhang, Dalton Trans., 2010, 39, 3273-3278.

77 S. Anandan, G.-L. Lee, P.- K. Chen, C. Fan and J. J. Wu, Ind. Eng. Chem. Res., 2010, 49, 9729-9737.

78 N. Liang, J. Zai, M. Xu, Q. Zhu, X. Wei and X. Qian, J. Mater. Chem. A, 2014, 2, 4208-4216.

79 D.-H. Wang, G.-Q. Gao, Y.-W. Zhang, L.-S. Zhou, A.-W. Xu and W. Chen, Nanoscale, 2012, 4, 7780-7785.

80 M. Xiong, L. Chen, Q. Yuan, J. He, S.-L. Luo, C.-T. Au and S.-F. Yin, Dalton Trans., 2014, 43, 8331-8337.

81 J. Tang, D. Li, Z. Feng, Z. Tan and B. Ou, RSC Adv., 2014, 4, 2151-2154.

82 B. G. S. Raj, R. N. R. Ramprasad, A. M. Asiri, J. J. Wu and S. Anandan, Electrochim. Acta, 2015, 156, 127-137.

83 D. Wang, Q. Wang and T. Wang, Nanotechnology, 2011, 22, 135604.

84 M. Toupin, T. Brousse and D. Bélanger, Chem. Mater., 2002, 14, 3946-3952.

85 W. Sugimoto, H. Iwata, Y. Yasunaga, Y. Murakami and Y. Takasu, Angew. Chem., 2003, 115, 4226-4230.

86 Y. Liu, W. Wang, Y. Wang, Y. Ying, L. Sun and X. Peng, RSC Adv., 2014, 4, 16374-16379. 